\title{
Treinamento da Habilidade Metacognitiva de Monito- ramento do Conhecimento em Sistemas Tutores
}

\author{
Title: Training of the Metacognitive Skill of Knowledge Monitoring in Tutoring Systems
}

Tiago Roberto Kautzmann

Programa Interdisciplinar de Pós-Graduação em

Computação Aplicada (PIPCA)

Universidade do Vale do Rio dos Sinos (UNI-

SINOS)

tkautzmann@gmail.com

\author{
Patrícia A. Jaques \\ Programa Interdisciplinar de Pós-Graduação em \\ Computação Aplicada (PIPCA) \\ Universidade do Vale do Rio dos Sinos (UNI- \\ SINOS) \\ pjaques@unisinos.br
}

\begin{abstract}
Resumo Alunos que possuem habilidades metacognitivas estudam mais estrategicamente, buscam o conhecimento em áreas deficitárias e controlam sua aprendizagem. A habilidade fundamental para o desenvolvimento de outras habilidades metacognitivas é a de monitoramento do conhecimento. Apesar de diversos trabalhos encorajarem os estudantes a monitorarem o próprio conhecimento, não se conhece estudos que investigaram os efeitos de um treinamento específico desta habilidade. Além disso, sabe-se que uma característica fundamental para o sucesso do treinamento metacognitivo é a sua individualização. Porém, não se tem conhecimento de estudos envolvendo ambientes computacionais de aprendizagem que adaptem a etapa do treinamento de reflexão do conhecimento a características do aprendiz. O presente estudo propõe um treinamento adaptativo especifico da habilidade de monitoramento do conhecimento em sistemas tutores inteligentes. Um agente pedagógico animado que realiza o treinamento proposto foi implementado e integrado a um sistema tutor algébrico. Os resultados de uma avaliação experimental sugerem que os alunos que receberam o treinamento proposto melhoraram a habilidade de monitoramento do conhecimento e o desempenho no domínio.
\end{abstract}

Palavras-Chave: Habilidade de Monitoramento do Conhecimento, Metacognição, Agente Pedagógico Animado, Sistemas Tutores Inteligentes

\begin{abstract}
Students who have metacognitive skills study more strategically, try to improve their knowledge in deficit areas and control their learning. Knowledge monitoring is a fundamental skill for the development of the other metacognitive abilities. Although several works have encouraged students to monitor their own knowledge, we are not aware of other studies that have investigated the effects of a specific training in knowledge monitoring. Furthermore, for the metacognitive training to be effective, it should be personalized. However, studies involving computer-aided instruction that provides adaptive training for the knowledge monitoring skill are still unknown. This paper proposes an adaptive training of knowledge monitoring skill in intelligent tutoring systems. An animated pedagogical agent that performs the proposed training was implemented and integrated into an algebraic tutoring system. Results of a classroom evaluation study suggest that students who received metacognitive training improved their knowledge monitoring skill and performed better on tests.
\end{abstract}

Keywords: Knowledge Monitoring Skill, Metacognition, Animated Pedagogical Agent, Intelligent Tutoring Systems

DOI: 10.5753/RBIE.2016.24.02.22 


\section{Introdução}

Estudos recentes que buscam melhorar a aprendizagem dos alunos têm cada vez mais considerado os aspectos metacognitivos nas estratégias de ensino. Em outras palavras, estes trabalhos têm analisado como o conhecimento dos aprendizes sobre os seus próprios processos cognitivos impacta na sua aprendizagem. Além de ensinar conteúdos de um determinado domínio, como Física ou Matemática, parte desses estudos busca melhorar habilidades metacognitivas específicas, como fazer o aluno conseguir identificar estratégias de estudo que o fazem aprender mais.

Outros estudos buscam melhorar as chamadas habilidades autorregulatórias. A autorregulação se refere ao direcionamento de esforços pessoais para a aquisição de conhecimentos e habilidades, sem depender de professores, pais ou outros agentes pedagógicos. Aprendizes autorregulados são proativos na definição de metas, na seleção e utilização de estratégias de estudo, no monitoramento da efetividade de suas ações e no controle da aprendizagem [5]. Os alunos são autorregulados à medida que são participantes metacognitivos ativos em sua aprendizagem [4]. Assim, a aprendizagem autorregulada é subordinada à metacognição, pois incorpora aspectos metacognitivos, como o monitoramento e o controle da cognição. Presume-se, portanto, que aprendizes autorregulados sejam aprendizes metacognitivos [54].

Estudos de Schoenfeld [2] demonstram a importância do emprego das habilidades metacognitivas na aprendizagem. Uma das descobertas de Schoenfeld é que aprendizes eficientes na solução de problemas matemáticos passam mais tempo refletindo sobre os problemas do que os alunos ineficientes. Ele observou que mesmo os estudantes que tinham conhecimentos matemáticos suficientes para resolver os problemas, poderiam apresentar um comportamento ineficiente por não passarem um tempo refletindo sobre o problema. Apesar desses alunos terem a oportunidade de pararem o que estavam fazendo e refletirem se determinada estratégia estava levando a uma solução ou, ainda, se perguntarem se deveriam tentar outra estratégia para o problema, eles não faziam estas ações. Estes aprendizes ineficientes dedicavam muito tempo tentando resolver os problemas, mas pouco tempo refletindo sobre os problemas.

Além disso, estudos realizados durante duas décadas, com alguns dos principais achados descritos em [63], sugerem que a habilidade metacognitiva fundamental para a aquisição das demais habilidades metacognitivas é a de monitoramento do conhecimento. Esta é a habilidade de uma pessoa de identificar o que sabe e o que não sabe sobre determinado assunto. Sabe-se que esta habilidade influencia o sucesso acadêmico em todos os níveis de ensino [63]. Além disso, alunos que são capazes de identificarem precisamente seu conhecimento em determinado conteúdo são mais propensos a se engajarem na aquisição dos conhecimentos deficitários [56], a buscarem ajuda quando necessário [31] e a estudarem mais estrategicamente [63].

Diversos trabalhos envolvendo ambientes computacionais de aprendizagem buscam, em dado momento da instrução, encorajar o aluno a refletir sobre o seu conhecimento $[12,64,8,6,52,53,51,16]$. No entanto, estes trabalhos não avaliam o efeito de um treinamento exclusivo da habilidade metacognitiva do monitoramento do conhecimento. Dessa forma, os efeitos isolados de um treinamento que promove especificamente esta habilidade metacognitiva são ainda desconhecidos no contexto de ambientes computacionais de aprendizagem.

Sabe-se que os alunos podem ser ensinados a melhorarem sua metacognição $[1,7]$ e, provavelmente, sua habilidade metacognitiva de monitoramento do conhecimento [62]. Igualmente, é conhecida a demanda por estudos que avaliem os efeitos de um treinamento específico desta habilidade metacognitiva em ambientes computacionais de aprendizagem. Dessa forma, o presente trabalho descreve um modelo computacional de treinamento da habilidade metacognitiva de monitoramento do conhecimento para sistemas tutores inteligentes. $\mathrm{O}$ estudo pretende investigar os efeitos de um treinamento específico do monitoramento do conhecimento em sistemas computacionais de aprendizagem, encorajando os estudantes a monitorarem o seu conhecimento durante o processo de resolução de problemas.

Outra característica importante do treinamento descrito no presente trabalho é a sua característica adaptativa. O conteúdo e a frequência de intervenções do treinamento proposto são adaptados ao nível metacognitivo de monitoramento do conhecimento do aluno, ao seu desempenho na resolução dos problemas apresentados e a seu histórico de resolução de problemas. Não se tem conhecimentos de outros trabalhos que adaptam o treinamento do monitoramento do conhecimento a características do aprendiz. Esta é uma propriedade importante pois o treinamento de habilidades metacognitivas deve ser individualizado ao aluno, ou seja, deve ser adaptado a características do aprendiz. [50] encontrou que o treinamento adaptativo aumenta a frequência com que os alunos empregam estratégias metacognitivas.

Para fins de avaliação, o modelo computacional proposto de treinamento da habilidade de monitoramento do conhecimento foi implementado como um agente pedagógico animado e integrado a um sistema tutor inteligente algébrico do tipo step-based, ou seja, que acompanha os 
passos de resolução do aluno. A integração do treinamento a um sistema tutor inteligente se justifica pelo fato desses sistemas possuírem módulos inteligentes que inferem o conhecimento do aprendiz, entre outras informações, o que permite a implementação das características adaptativas do treinamento metacognitivo.

A avaliação do sistema ocorreu em duas etapas: a primeira formativa e a segunda somativa [44]. A avaliação formativa buscou avaliar a usabilidade e funcionamento do sistema, além do comportamento dos alunos durante as sessões. Ela envolveu três sessões com um grupo de 17 alunos de uma escola particular da região do Vale dos Sinos, no Rio Grande do Sul. Após a avaliação formativa, foram realizadas alguns ajustes no sistema.

A avaliação somativa buscou verificar se o treinamento da habilidade de monitoramento do conhecimento em sistemas tutores leva a uma melhora dessa habilidade e da aprendizagem dos estudantes. O estudo experimental seguiu um design pré e pós-testes com grupos de controle e experimental e teve a participação de 107 alunos de quatro escolas particulares no município de São Leopoldo, no Rio Grande do Sul, que usaram o sistema durante seis a sete sessões de uma hora de duração. $\mathrm{O}$ experimento buscou responder as seguintes questões de pesquisa: (1) o treinamento fornecido pelo agente melhora a habilidade metacognitiva de monitoramento do conhecimento?; (2) o treinamento fornecido pelo agente melhora o desempenho no domínio?; (3) pode ser encontrada uma correlação entre a habilidade de monitoramento do conhecimento e o desempenho no domínio? Esta correlação já foi encontrada em sala de aula [63], mas não em ambientes computacionais de aprendizagem e, mais especificamente, em STIs.

O presente artigo está organizado como segue. A seção 2 apresenta a fundamentação teórica sobre os principais conceitos relacionados à metacognição e à habilidade de monitoramento do conhecimento e descreve características e achados científicos sobre o treinamento de habilidades metacognitivas. A seção 3 descreve os sistemas tutores inteligentes, que são os ambientes computacionais utilizados no treinamento metacognitivo do presente estudo. A seção 3 também apresenta o sistema tutor de álgebra PAT2Math, empregado nas avaliações. A seção 4 possui a fundamentação teórica sobre os agentes pedagógicos animados e a seção 5 descreve os trabalhos relacionados. A seção 6 apresenta o agente de treinamento da habilidade de monitoramento do conhecimento proposto. É descrito o mecanismo de avaliação do nível corrente do aluno na habilidade de monitoramento do conhecimento, os mecanismos de funcionamento do agente, e a implementação e integração do agente no sistema tutor algébrico PAT2Math. Os estudos de avaliação são descritos na seção 7. Os resultados da avaliação somativa são apresentados na seção 8 . A seção 9 traz uma discussão sobre os resultados e as conclusões do estudo são descritas na seção 10 .

\section{Metacognição}

John Flavell, provavelmente o primeiro pesquisador a utilizar o termo metacognição [19], descreve o construto ${ }^{1}$ como o conhecimento de uma pessoa sobre os próprios processos e produtos cognitivos ou qualquer coisa relacionada a eles [27]. Uma versão resumida define a metacognição como os pensamentos sobre os próprios pensamentos [26]. Um exemplo bastante simples para compreender o conceito é quando uma pessoa decide fazer uma lista de compras antes de ir ao supermercado, acreditando que teria dificuldade de recordar todos os produtos de que necessita. Compreender os limites da memória é uma forma de metacognição.

Segundo Pintrich, Wolters e Baxter [48] e Dunlosky e Metcalfe [25], os processos metacognitivos podem ser divididos em três componentes principais: (1) conhecimento metacognitivo; (2) julgamento e monitoramento dos próprios processos de aprendizagem; (3) autorregulação e controle da cognição.

O conhecimento metacognitivo consiste principalmente de conhecimentos ou crenças sobre os fatores ou variáveis que agem e interagem de forma que afetem o curso e os resultados dos empreendimentos cognitivos [26]. Por exemplo, a crença de uma pessoa que ela aprende melhor escutando do que lendo. Outro exemplo é a crença de que uma boa forma de aprender e reter uma quantidade grande de informações é prestar atenção nos pontos principais e tentar repeti-los para si mesmo com suas próprias palavras [26]. O componente metacognitivo de julgamento e monitoramento dos próprios processos de aprendizagem se refere à avaliação do aluno sobre o andamento ou do atual estado de uma determinada atividade cognitiva [25]. Um exemplo é a súbita percepção de uma pessoa de que não está entendendo o que está lendo. O componente metacognitivo de autorregulação e controle da cognição se refere às atividades que os indivíduos se engajam a fim de adaptar e mudar sua cognição ou comportamento para uma melhora da aprendizagem [25]. Por exemplo, um aluno pode decidir parar uma atividade, continuá-la ou mudá-la durante seu andamento. Esta decisão está ligada aos dois componentes anteriores, pois após monitorar o andamento de uma atividade, o aluno pode inferir que não está obtendo progressos na aprendizagem, e esta inferência passa a ser um conhecimento metacognitivo. A partir de então, o estudante pode decidir modificar o andamento da atividade.

\footnotetext{
${ }^{1}$ Conceito teórico que não é diretamente observável [36].
} 


\subsection{Habilidade metacognitiva de monitora- mento do conhecimento}

Nas últimas décadas, o grupo de pesquisa de Tobias e Everson desenvolveu estudos que buscaram entender um aspecto da metacognição, o monitoramento do conhecimento. Esta habilidade tem relação com o segundo componente metacognitivo descrito anteriormente, e se refere à habilidade do aluno de identificar precisamente o que sabe e o que não sabe sobre determinado conteúdo ou assunto [63]. A hipótese inicial do trabalho dos pesquisadores era de que alunos que não pudessem diferenciar entre o que sabem e o que não sabem dificilmente se engajariam em atividades metacognitivas, como avaliar sua aprendizagem, fazer planos para a aprendizagem e empregar estratégias de estudo mais eficientes. Estudos realizados durante vários anos, descritos em [63], apontaram positivamente para a hipótese inicial dos pesquisadores.

Segundo Tobias e Everson [63], a tarefa do aluno de monitorar o seu conhecimento é complexa. O aluno precisa recuperar o conhecimento declarativo ou procedural da memória de longo prazo, compará-lo com o material do problema que lhe é apresentado, e fazer um julgamento, se possui conhecimento para resolver o problema. Ullman descreve, em [41], os conhecimentos declarativo e procedural. O conhecimento declarativo está relacionado a conhecimentos sobre fatos (conhecimento semântico) e eventos (memória episódica), e parte deste conhecimento pode ser lembrado conscientemente. O conhecimento procedural geralmente não está disponível para acesso consciente, e tem relação, entre outras coisas, às habilidades, como a habilidade em jogos de videogame e a habilidade para andar de bicicleta.



Figura 1: Modelo de metacognição de Tobias e Everson

A Figura 1 apresenta um modelo hierárquico desenvolvido por Tobias e Everson, em que a capacidade metacognitiva de monitoramento do conhecimento é um prérequisito para ativar outras habilidades metacognitivas
[63].

Alguns estudos descrevem os benefícios observados em alunos conscientes sobre o seu conhecimento: permite que possam dar o primeiro passo para remediar suas áreas de conhecimento deficitárias [56]; tem mais probabilidade de buscar ajuda acadêmica quando necessário [31]; estudam mais estrategicamente [63]. Além disso, a capacidade do aluno de monitorar o conhecimento tem relação com o sucesso na aprendizagem no Ensino Fundamental, Ensino Médio, Ensino Médio profissionalizante e Ensino Superior [61]. O estudo apresentado em [13] corrobora com os achados dos estudos anteriormente citados, descrevendo que uma das características dos aprendizes efetivos é que eles são realistas sobre seus pontos fortes e fracos.

\subsection{Treinamento metacognitivo}

Instrução é a manipulação realizada por um instrutor no ambiente do aprendiz com o objetivo de promover a aprendizagem, ajudando o aluno a aprender algo [55]. Manipular o ambiente significa manipular as experiências do aprendiz através de falas, gestos ou outros métodos instrucionais. Com isso, a instrução metacognitiva pretendida no presente trabalho visa manipular o ambiente de aprendizagem buscando desenvolver no aluno a habilidade metacognitiva de monitoramento do conhecimento.

Veenman, Hout-Wolters e Afflerbach apresentam três princípios fundamentais para o sucesso de uma instrução metacognitiva [42]: (1) inserir a instrução metacognitiva no conteúdo da instrução sobre determinado assunto para garantir conectividade; (2) informar os alunos sobre a utilidade das ações metacognitivas para fazê-los empregar esforço inicial; e (3) treinamento prolongado para garantir a aplicação da atividade metacognitiva.

Outra propriedade importante no treinamento metacognitivo em ambientes computacionais de aprendizagem é a adaptação da instrução a características do aluno [50]. Neste contexto adaptativo, um conceito tradicionalmente utilizado para referenciar o processo de assistência prestado ao aluno por um professor, de forma que a assistência seja adaptada de acordo com as necessidades do aluno, é o de scaffolding. No scaffolding, a modificação das tarefas às necessidades do aluno objetiva atingir as metas da aprendizagem, de forma que se o processo não fosse modificado, o aluno não conseguiria alcançar tais metas [3]. O scaffolding é baseado no conceito de Vygotsky [35] sobre a Zona de Desenvolvimento Proximal (ZDP), em que pessoas (professores, pais, colegas) mais competentes em determinado domínio de conhecimento ajudam o aprendiz fornecendo informação e apoio temporário. Este suporte é gradualmente diminuído à medida que aumenta a competência do aluno. 
Em ambientes de aprendizagem computacionais, o termo scaffolding também tem sido utilizado para se referir aos ambientes computacionais que orientam os alunos no processo de aprendizagem [50,3]. O scaffolding pode fornecer apoio aos alunos através de modelos, sugestões, prompts, dicas, soluções parciais, entre outros [20]. O scaffolding implementado no presente estudo é entregue ao aluno através dos seguintes recursos: prompts, feedbacks e self-explanations. Além disso, o auxílio prestado ao aprendiz é diminuído à medida que o aluno melhora a sua habilidade metacognitiva de monitorar seu conhecimento.

Os prompts são recursos instrucionais que auxiliam os estudantes a focarem sua atenção sobre seus próprios pensamentos e a entender suas próprias atividades durante a aprendizagem $[37,15]$. Em outras palavras, os prompts servem para guiar a atenção dos alunos para seus pensamentos e construir um entendimento das tarefas do domínio [66]. Nesse sentido, os prompts também podem ser metacognitivos, encorajando os estudantes a refletirem sobre os seus próprios pensamentos [15]. No presente trabalho, os prompts são entregues aos aprendizes por um agente pedagógico animado através de mensagens textuais em balões de fala, com o objetivo de encorajá-los a refletir sobre seu conhecimento.

Os feedbacks são informações entregues ao aluno sobre resultados ou avaliações das suas ações, e é considerado um importante recurso de ensino [20], melhorando a aprendizagem e proporcionado resultados mais rápidos [30]. No presente estudo, os feedbacks são entregues ao aluno como mensagens de texto para notifica-lo sobre algum comportamento inadequado e sobre o seu nível corrente da habilidade de monitoramento do conhecimento.

O Self-explanation é um processo em que o aluno explica algo para si mesmo. Estudos apontam que os estudantes aprendem mais quando eles explicam os materiais instrucionais para si mesmos $[39,38,29]$. Sabendo que nem todos os alunos se engajam espontaneamente nestas atividades de self-explanations [39], é possível encorajalos através de prompts [40]. No presente estudo, as atividades de self-explanations objetivam fazer o aprendiz refletir, escrevendo com suas próprias palavras, em formulários de texto, sobre como ele monitorou o seu conhecimento nos problemas anteriores.

O conteúdo e a frequência com que os recursos de scaffolding são entregues são adaptados ao aluno. Neste contexto, os sistemas tutores inteligentes permitem a implementação de ambientes de aprendizagem que adaptam a instrução e assistência de acordo com o conhecimento e outras características inferidas do aprendiz, através de seus módulos inteligentes. Os STIs serão abordados na próxima seção.

\section{Sistemas Tutores Inteligentes}

Nas últimas décadas, inúmeros esforços têm sido realizados em estudos que buscam melhorar a aprendizagem dos alunos através do desenvolvimento de sistemas computacionais que empregam conhecimentos multidisciplinares, de campos de estudo como a Inteligência Artificial, a Ciência Cognitiva e a Educação. Um dos objetivos de aplicar a Inteligência Artificial na Educação é desenvolver softwares que simulam o raciocínio dos professores e a aprendizagem dos alunos [9]. Os Sistemas Tutores Inteligentes (STIs) se encaixam neste contexto, pois são ambientes de aprendizagem inteligentes que provêm assistência individualizada aos estudantes. Estes sistemas possuem módulos que representam o conhecimento especialista capaz de resolver os problemas apresentados aos alunos, além de simular comportamentos de tutoria capazes de adequar o ensino às necessidades dos aprendizes. Dessa forma, as decisões pedagógicas podem ser adaptadas pelo STI de acordo com os resultados coletados da interação do aluno com o sistema. $\mathrm{O}$ aluno interage várias vezes com o STI, e a cada vez que o aluno interage com o sistema, o STI pode ajustar sua interface, mensagens, tipos e complexidade dos problemas ofertados, adaptando as experiências de aprendizagem dos alunos.

As possibilidades adaptativas dos STIs permitem que esses sistemas possam ser utilizados para a prática da condição de ensino one-to-one tutoring, em que cada aluno aprende com seu próprio tutor. Em 1984, o trabalho de Bloom [10] comparou três diferentes condições instrucionais: convencional, mastery learning e one-to-one tutoring. Na condição convencional, os alunos aprendem os conteúdos em turmas com cerca de 30 alunos por professor. Na condição de mastery learning, os alunos também aprendem os conteúdos em turmas com cerca de 30 alunos por professor, mas recebem feedback seguido de procedimentos corretivos e testes paralelos para determinar uma medida do domínio dos alunos sobre o assunto. Na condição de one-to-one tutoring, a instrução segue os mesmos procedimentos da condição mastery learning, com a diferença que cada aluno aprende com seu próprio tutor humano, ou seja, um tutor por aluno. Bloom encontrou que na condição one-to-one tutoring o desempenho dos alunos foi $98 \%$, ou 2 desvios padrão, superior ao desempenho dos alunos na condição convencional, indicando que a condição one-to-one tutoring é a melhor forma de aprender.

Estudos recentes reforçam a importância desses sistemas para o ensino, pois descobriram que os STIs são tão efetivos quanto os tutores humanos em uma instrução individualizada. O estudo de VanLehn [33] realiza uma meta-análise, combinando os resultados de outros estudos encontrados na literatura. $\mathrm{O}$ autor descreve que a crença comum entre os pesquisadores era de que a tutoria huma- 
na (individualizada) tinha efeito de dois desvios padrão superiores aos cenários sem tutoria (condição convencional sem feedbacks e procedimentos corretivos). Outras crenças indicavam que os STIs eram melhores em 1,0 desvio padrão do que os cenários sem tutoria. $\mathrm{O}$ estudo de VanLehn não confirma estas crenças e apresenta resultados que indicam que o efeito da tutoria humana em relação à condição sem tutoria é muito menor, com 0,79 de desvio padrão. Ele encontrou também o efeito 0,76 de desvio padrão para STIs do tipo step-based, valor muito próximo daquele encontrado para os tutores humanos. Importante ressaltar que estes resultados foram encontrados para STIs do tipo step-based, que acompanham os passos de solução dos alunos durante a resolução de problemas, podendo fornecer assistência em cada um desses passos dos aprendizes. O trabalho de meta-análise de Ma e colegas [65] não encontrou diferenças significativas no desempenho dos alunos na aprendizagem com STIs e a aprendizagem através de tutoria humana, quando o sistema realiza uma seleção individualizada de problemas, prompts e feedbacks que são entregues ao aprendiz. Por fim, os estudos de meta-análise descritos em [58, 59] também encontraram que os STIs podem ser tão efetivos quanto um professor particular.

Para compreender como os STIs implementam a característica adaptativa, que permite a individualização do ensino, é necessário conhecer a arquitetura básica desses sistemas tutores. Segundo Burns e Capps [21], os STIs devem ter conhecimento sobre o domínio a ser ensinado, de forma que possam fazer inferências ou, até mesmo, resolver os problemas no domínio. Devem também ser capazes de deduzir o conhecimento aproximado do aluno e possuir estratégias inteligentes para diminuir as diferenças entre o desempenho de um especialista e de um aprendiz. Os trabalhos [9] e [21, 28] descrevem a arquitetura básica de um STI com quatro módulos: Módulo do Domínio, Módulo do Aluno, Módulo de Tutoria e Módulo de Comunicação. O Módulo do Aluno é frequentemente chamado de Modelo do Aluno [32].

O Módulo do Domínio representa o conhecimento especialista em um determinado domínio, ou seja, representa o desempenho de um especialista em uma determinada área de estudo do sistema, como na resolução de problemas de Matemática ou de Física [9]. O Modelo do Aluno observa o comportamento do aluno e cria uma representação para o seu conhecimento [9]. O Modelo do Aluno armazena informações inferidas sobre o aprendiz, como estimativas sobre traços do aluno (conhecimento específico, estilo de aprendizagem), escores sobre testes, quantidade de erros ou de ajudas solicitadas, duração de tempo que o aluno se dedicou na resolução de problemas, além de outras informações [32], como informações relativas ao estado afetivo (engajamento, tédio, frustração, nível de concentração, entre outros) [9]. O Módulo de Tutoria representa as estratégias de ensino e o conhecimento curricular e instrucional, como descrito em [9] e [21]. Além de adaptar a instrução de acordo com as características do aluno, inferidas e mantidas pelo Modelo de Aluno, o tutor também poderá considerar os objetivos e estratégias instrucionais do Módulo de Tutoria [9]. Por fim, o Módulo de Comunicação é responsável pela comunicação do aluno com o tutor através da interface gráfica do sistema.

VanLehn [32] organiza o funcionamento de um STI em duas iterações: inner loop e outer loop. O outer loop funciona selecionando problemas para o aluno. A estratégia mais simples de outer loop apresenta uma lista de problemas ao aluno, e é o aprendiz que escolhe o próximo problema a ser resolvido. Em um exemplo de estratégia mais inteligente de outer loop, conhecida como macroadaption, o sistema sabe quais conhecimentos são exercitados em determinado problema, e sabe a estimativa do grau de domínio do aluno para os mesmos conhecimentos exigidos pelo problema. Desta forma, o mecanismo de outer loop pode selecionar problemas que envolvem conhecimentos que o aluno não domina ou que não domina totalmente. O inner loop, por sua vez, funciona sobre os passos dos problemas. O inner loop acompanha cada passo de resolução do aluno para os problemas, podendo, a cada passo, fazer intervenções, como apresentar dicas e feedbacks e avaliar o conhecimento do aprendiz. O inner loop corresponde às iterações internas do outer loop, de forma que cada iteração do outer loop pode ter várias iterações do inner loop.

\subsection{PAT2Math}

O PAT2Math (Personal Affective Tutor to Math) ${ }^{1}$ é um sistema tutor inteligente que assiste os alunos na resolução de equações de $1^{\circ}$ e $2^{\circ}$ graus com uma incógnita. O PAT2Math é um sistema tutor do tipo step-based, ou seja, é projetado para permitir que os estudantes entrem com os passos da solução dos problemas apresentados a eles [32]. O sistema é capaz de resolver equações algébricas, corrigir os passos do aluno, exibir feedbacks que auxiliam o aprendiz a resolver os passos e permite que o aluno solicite dicas. O sistema também é capaz de inferir o conhecimento do aluno no domínio (apenas para conhecimentos relacionados a equações de $1^{\circ}$ grau) e guardar um histórico de resolução de equações do aprendiz.

O PAT2Math possui um sistema especialista (SE) responsável por corrigir equações algébricas e verificar se os passos do aluno são corretos. O SE também é capaz de gerar vários passos que o aluno poderia utilizar para resolver o problema. O sistema compara o passo do aluno com todos os passos possíveis, retornando uma classifi-

\footnotetext{
${ }^{1}$ Disponível online em http://pat2math.unisinos.br.
} 
cação como "correto" ou "incorreto" e as unidades de conhecimento que o aluno provavelmente utilizou para derivar o passo. Além disso, como o SE consegue gerar os próximos passos possíveis para o problema, ele também consegue retornar todas as unidades de conhecimento possíveis de serem aplicadas em um próximo passo [46]. As unidades de conhecimento citadas anteriormente podem ser operações aritméticas e algébricas, como adição, multiplicação, simplificação, princípio aditivo; ou conceitos, como propriedade comutativa e igualdade dos membros. O SE do PAT2Math foi desenvolvido como um sistema baseado em regras de produção através de uma shell de sistema especialista implementada na linguagem de programação Java [22].

O Modelo de Aluno do PAT2Math guarda as seguintes informações sobre o aluno: (1) informações sobre o perfil do aprendiz, como nome, turma e escola; (2) histórico de passos do aluno na resolução de equações, com as respectivas unidades de conhecimento aplicadas por ele; (3) valores numéricos relacionados à probabilidade de domínio do aluno em cada uma das unidades de conhecimento em equações algébricas de $1^{\circ}$ grau. Os valores referentes à probabilidade do aluno dominar cada unidade de conhecimento são inferidos pelo Modelo de Aluno através de um módulo, descrito em [23], que infere o conhecimento algébrico do aprendiz relacionando conceitos, operações e falsas concepções do aluno no domínio de equações de $1^{\circ}$ grau. Este módulo de inferência de conhecimento utiliza uma estrutura de Redes Bayesianas Dinâmicas (RBD), que são estruturas probabilísticas frequentemente utilizadas na avaliação do conhecimento dos aprendizes [23].

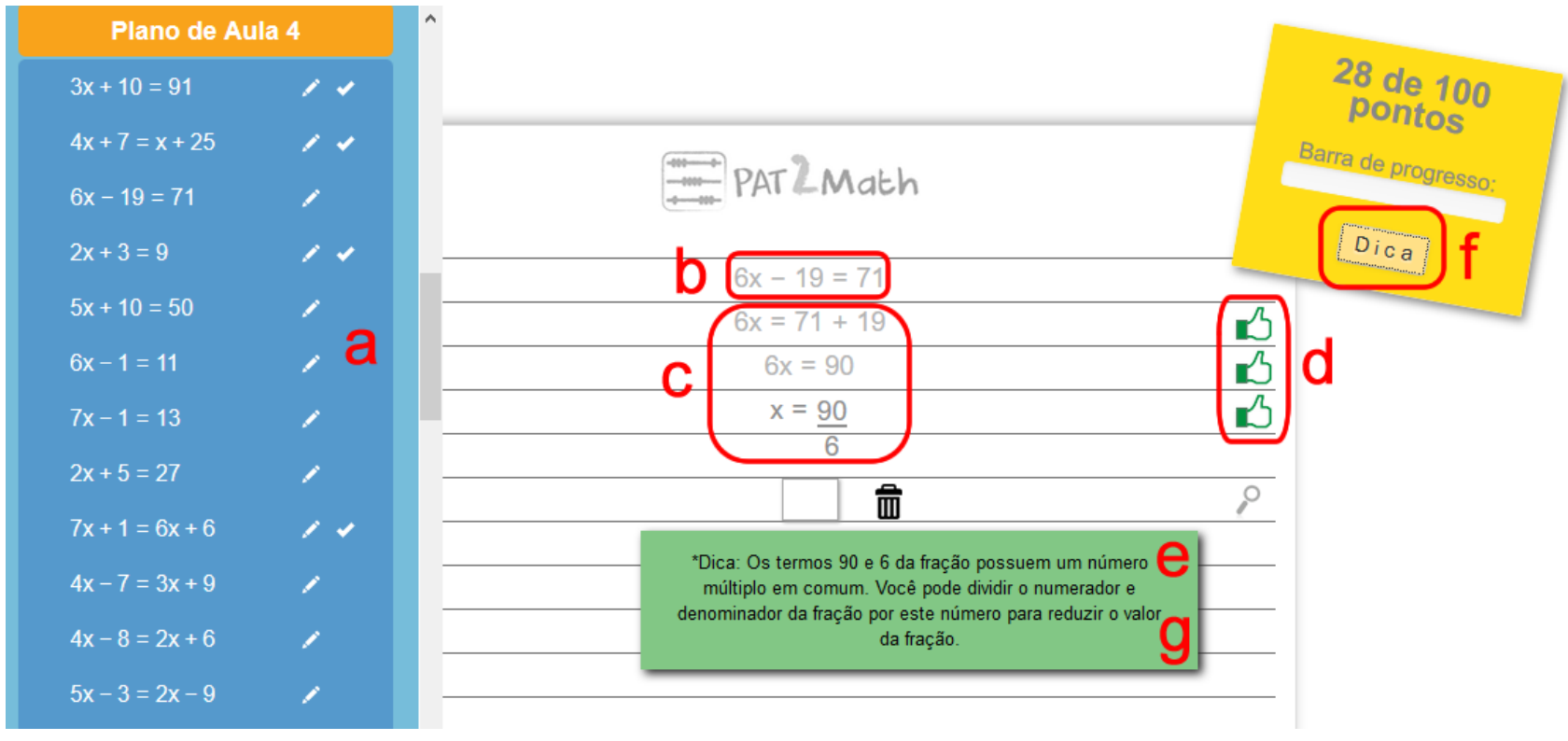

Figura 2: Interface do PATEquation

O PAT2Math possui um editor de álgebra denominado PATEquation (Figura 2) que auxilia o aluno no aprendizado e é responsável pela comunicação entre o aprendiz e o STI [46]. Este componente apresenta as equações na interface gráfica, possibilita que o aluno entre com os passos no processo de resolução e exibe dicas e feedbacks. De acordo com a Figura 2: (a) o aluno seleciona uma equação, dentre várias equações listadas na interface gráfica, através de planos de aula; (b) a equação é exibida; (c) o aluno entra com os passos de resolução da equação; (d) um feedback mínimo é exibido para cada passo, indicando se o passo é correto ou não; (e) se o passo está incorreto, é dada uma mensagem de feedback explicando ao estudante como corrigir a sua solução; (f) o aluno pode solicitar dicas quando não souber como prosseguir em cada passo; (g) a dica é exibida quando o aluno a solicita.

Por fim, para resumir as funcionalidades da versão atual, o PAT2Math é composto pelo PATEquation, que representa o inner loop do STI, como descrito em [32], uma vez que é nesse componente do PAT2Math que o estudante fornece os passos das equações e recebe dicas e feedbacks para esses mesmos passos. No mecanismo de outer loop, as equações são disponibilizadas pelo sistema em forma de listas de problemas e são escolhidas para resolução pelo próprio aluno. Cada lista de problemas é chamada de plano. Cada plano possui níveis de complexidade diferentes. Além disso, possui um sistema especialista que resolve equações de $1^{\circ}$ e $2^{\circ}$ graus com uma incógnita, corrige os passos do aluno e identifica as uni- 
dades de conhecimento utilizadas e algumas falsas concepções. O sistema também mantém um histórico de resolução de passos de cada aprendiz e infere e guarda o conhecimento do estudante no domínio de equações de $1^{\circ}$ grau.

\section{Agentes Pedagógicos Animados}

Russel e Norvig descrevem a Inteligência Artificial como o subcampo da Ciência da Computação que visa construir agentes que apresentam aspectos de comportamento inteligente [57]. O conceito de agente é central na Inteligência Artificial [57] e podem ser descritos como programas de software que demonstram comportamento adaptativo, independente e orientado a objetivos [45] e capazes de perceber o ambiente através de sensores e agir através de atuadores [57]. Neste contexto, os agentes pedagógicos tem um papel pedagógico ou educacional para facilitar ou melhorar a aprendizagem [14]. Estes agentes podem ser modelados como agentes pedagógicos animados que interagem com o usuário. Um agente pedagógico animado (APA) é um agente inteligente com função pedagógica, representado por um personagem animado [47] que simula a presença de um professor [24]. A presença de APAs possibilita que as interações do aluno com o sistema ocorram de forma mais natural e antropomórfica, levando a um maior engajamento por parte dos estudantes e a uma melhora na aprendizagem [24].

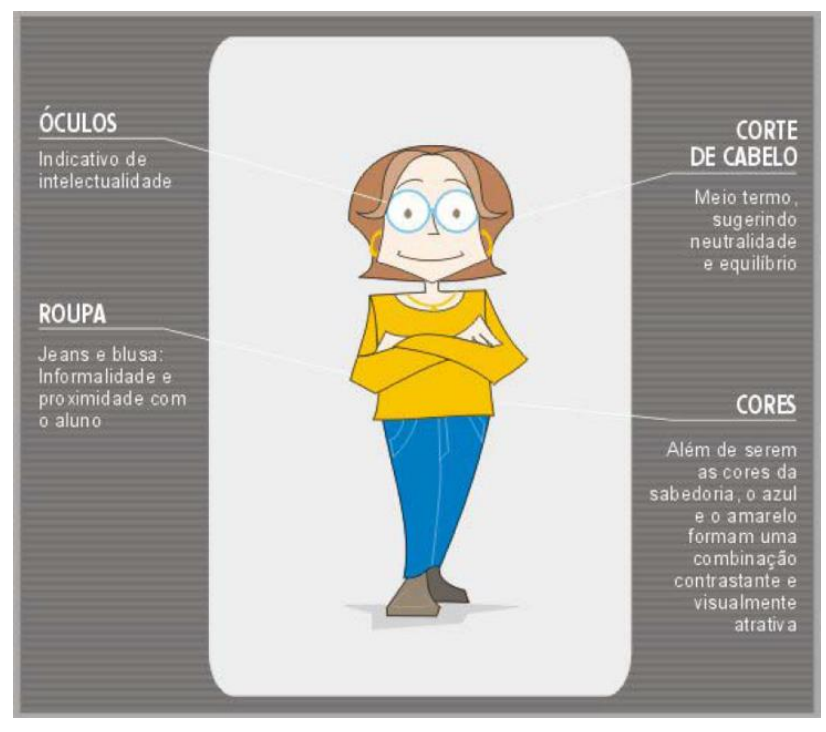

Figura 3: Agente Pedagógico Animado PAT

No presente trabalho, o APA possui a função específica de exibir as mensagens relacionadas às ações instrucionais do treinamento metacognitivo. Mais especificamente, ele mostra as mensagens textuais de prompts metacognitivos, feedbacks e mensagens explicando a importância da aplicação da habilidade metacognitiva durante o aprendizado. Estas mensagens são entregues como balões de fala. O personagem animado utilizado para o APA do presente trabalho foi criado por Bocca, como descrito em [17], e se chama PAT (Pedagogical and Affective Tutor). PAT é um personagem $2 \mathrm{D}$ de gênero feminino, possui corpo inteiro, aparece na interface gráfica todo o tempo em que o aluno está no sistema, e possui expressões faciais relacionadas à fala (como quando a mensagem textual de prompt metacognitivo é exibida), espera e outras expressões como acenos e piscadas. O personagem PAT pode ser visualizado na Figura 3. A integração do APA com o sistema do presente trabalho é descrita na seção 6 .

\section{Trabalhos Relacionados}

O principal critério utilizado para a seleção dos trabalhos relacionados descritos nesta seção é que o treinamento deve encorajar explicitamente o aluno a refletir sobre o seu conhecimento, como por mensagens textuais apresentadas na interface gráfica do sistema. Dessa forma, alguns dos estudos selecionados não tinham, necessariamente, objetivos instrucionais específicos e explícitos relacionados à melhora da habilidade de monitoramento do conhecimento. No entanto, eles foram selecionados por, em algum momento da instrução fornecida, encorajar o aluno, de forma explícita, a refletir sobre o seu conhecimento. Este critério de seleção se justifica pelo fato de que um treinamento pode indiretamente melhorar habilidades do aluno que não estavam previstas nos objetivos instrucionais.

O trabalho descrito em [12] apresenta um modelo de treinamento de três habilidades metacognitivas, entre elas a de monitoramento do conhecimento. $O$ treinamento encoraja o aluno a monitorar o seu conhecimento, com mensagens explícitas na interface gráfica buscando levar o aluno a refletir sobre o seu conhecimento e explicando a importância das habilidades metacognitivas treinadas. No entanto, todas as atividades do treinamento seguem uma sequência fixa, ou seja, não são adaptadas a características do aprendiz. Este é o único trabalho relacionado que avaliou os benefícios do treinamento para a melhora da habilidade de monitoramento do conhecimento, mesmo que outras habilidades também tenham sido treinadas. Os resultados deste estudo foram inconclusivos, não sendo possível identificar um claro efeito positivo do treinamento para a melhora da habilidade de monitoramento do conhecimento. O trabalho apresentado em [16] descreve uma proposta de treinamento específico da habilidade de monitoramento do conhecimento em ambientes computacionais de aprendizagem. No entanto, este trabalho não implementou o treinamento e, consequentemente, não avaliou os efeitos do treinamento. Também não foram encontrados trabalhos que indiquem a continuidade deste estudo. O trabalho apresentado em [64] 
descreve o Help Tutor, um agente integrado a um sistema tutor inteligente que treina o comportamento de helpseeking, que é a habilidade de um indivíduo de buscar ajuda de professores, colegas, livros, entre outros, apenas quando esta ajuda é necessária. O trabalho com o Help Tutor tem relação com o presente estudo, pois se espera que os alunos que tenham um comportamento adequado de help-seeking consigam distinguir corretamente entre o que eles sabem e o que não sabem sobre determinado domínio de conhecimento [63]. O estudo em [8] descreve um modelo instrucional que busca melhorar habilidades investigativas dos alunos. Em uma das fases do treinamento, o sistema encoraja o aluno de forma explícita, através de mensagens na interface gráfica, a monitorar o seu conhecimento. [6] descreve o método de treinamento IMPROVE, que busca melhorar aspectos metacognitivos dos alunos. Em dado momento do treinamento, o método encoraja o aluno, de forma explícita, a refletir sobre o seu conhecimento. $\mathrm{O}$ trabalho descrito em $[53,51]$ possui um mecanismo que possibilita ao aluno que faça julgamentos de seu conhecimento. Por fim, o agente descrito em [52] permite que os estudantes julguem os seus conhecimentos e explica a importância para a aprendizagem quando o aprendiz consegue identificar a existência ou falta de conhecimento em determinado domínio de conhecimento.

Apenas dois trabalhos $[12,16]$ explicitam em seus objetivos instrucionais a melhora da habilidade de monitoramento do conhecimento, sendo que o trabalho relatado em [12] busca também treinar outras duas habilidades metacognitivas. Apenas o trabalho descrito em [12] avalia os efeitos do treinamento do monitoramento do conhecimento. Embora todos os trabalhos relacionados encorajem os alunos a refletirem sobre os seus conhecimentos, nenhum deles avaliou exclusivamente a habilidade de monitoramento do conhecimento. Dessa forma, os efeitos isolados de um treinamento específico objetivando encorajar os alunos a refletir sobre o seu conhecimento para promover a melhora da habilidade de monitoramento do conhecimento são ainda desconhecimentos. Além disso, a etapa do treinamento fornecido pelos estudos citados anteriormente relativa à reflexão do conhecimento não é adaptada a características dos alunos, como recomendado pelo estudo descrito em [50].

\section{Agente de treinamento da habilida- de metacognitiva de monitoramento do conhecimento}

O presente estudo objetiva investigar os efeitos de um treinamento específico da habilidade de monitoramento do conhecimento que adapta o conteúdo do treinamento e a frequência de intervenções do sistema de acordo com o nível corrente de habilidade de monitoramento do conhecimento do aluno, seu conhecimento no domínio e seu histórico de resolução de problemas. A assistência prestada ao aluno é diminuída à medida que o aluno demonstra competência na habilidade metacognitiva treinada $\mathrm{e}$ no desempenho no domínio. Para estas finalidades, foi desenvolvido um agente pedagógico animado que treina a habilidade de monitoramento do conhecimento em STIs do tipo step-based.

$\mathrm{O}$ agente pedagógico animado treina a habilidade de monitoramento do conhecimento através de mensagens textuais que encorajam o aluno a refletir sobre seu conhecimento. As seguintes estratégias instrucionais foram adotadas: (1) encorajar o aluno a identificar o que o problema está pedindo; (2) encorajar o aluno a dedicar algum tempo para refletir sobre o seu conhecimento antes de tentar um novo passo na resolução do problema; e (3) encorajar o aluno a refletir sobre problemas similares que foram resolvidos por ele anteriormente. Estas estratégias são discutidas nos trabalhos descritos em [11, 56, 34, 18$]$.

O treinamento adaptativo é uma importante característica do agente. Tanto o conteúdo do treinamento quanto a frequência das intervenções são adaptadas às seguintes informações do aluno: (1) seu nível de habilidade corrente de monitoramento do conhecimento; (2) seu conhecimento no domínio; e (3) seu histórico de resolução de problemas. Neste contexto adaptativo, o agente pode ser integrado a STIs que: (1) fornecem uma assistência passo-a-passo durante a resolução de problemas (STIs do tipo step-based); (2) mantém o histórico de resolução de problemas do aluno; (3) identificam os conhecimentos aplicados pelo aprendiz em cada passo e os conhecimentos que poderiam ser empregados em um próximo passo (por exemplo, STIs que empregam model tracing); e (4) inferem a probabilidade de conhecimento do aluno nas unidades de conhecimento do domínio. A forma como o agente utiliza estas características do STI são explicadas mais adiante.

O treinamento utiliza três tipos de ações de reflexão que são entregues pelo agente pedagógico animado na forma de balões de fala: (1) prompts que encorajam o aluno a refletir sobre seu conhecimento; (2) feedbacks que notificam o aprendiz sobre algum comportamento inadequado ou sobre seu nível corrente da habilidade de monitoramento do conhecimento; e (3) self-explanations que encorajam o estudante a escrever com suas próprias palavras como ele monitorou seu conhecimento.

\subsection{Avaliando a habilidade de monitoramen- to do conhecimento}

Com o objetivo de fornecer o treinamento adaptativo, o agente pedagógico precisa de um mecanismo que infira o nível corrente da habilidade de monitoramento do conhecimento do aluno. Este estudo utilizou um instrumento chamado Knowledge Monitoring Assessment (KMA), 
descrito em [11] e [60], que mede a habilidade do aprendiz de monitorar o próprio conhecimento. O KMA compara a avaliação do estudante sobre o seu próprio conhecimento para resolver um problema com a sua performance na solução do mesmo problema. $\mathrm{O}$ instrumento gera um total de quatro escores relativos ao desempenho do aluno em monitorar o seu conhecimento: (a) o aluno avalia que possui conhecimento para resolver o próximo passo do problema e consegue resolver corretamente $(++)$; (b) o aluno avalia que possui conhecimento para resolver o próximo passo do problema, mas não consegue resolver corretamente (+-); (c) o aluno avalia que não possui conhecimento para resolver o próximo passo do problema, mas consegue resolver corretamente (-+); e (d) $\mathrm{o}$ aluno avalia que não possui conhecimento para resolver o próximo passo do problema e não consegue resolver corretamente (--). Os escores ++ e -- são relativos a avaliações precisas do aluno sobre seu conhecimento, enquanto que os escores +- e -+ são relativos a avaliações imprecisas do aluno.
Para a definição dos escores KMA é utilizado apenas o histórico recente das avaliações KMA, sendo possível avaliar apenas o conhecimento metacognitivo recente do aluno, de forma que os desempenhos metacognitivos mais antigos não afetem a medida metacognitiva corrente. O presente trabalho considerou apenas as 15 últimas avaliações KMA, definindo pesos maiores para as avaliações mais recentes. Por exemplo, a avaliação KMA mais recente recebe peso 15 , o penúltimo recebe peso 14 . A $15^{\circ}$ avaliação mais recente recebe peso 1 . Considere o cenário hipotético da Tabela 1. Em 8 passos o aluno estimou que resolveria e resolveu, obtendo o valor $63(15+$ $12+11+8+6+5+4+2$ ) para o escore ++; em 2 passos estimou que resolveria e não resolveu, obtendo o valor $17(14+3)$ para o escore +-; em 1 passo estimou que não resolveria e resolveu, obtendo o valor 9 para o escore -+; em 4 passos estimou que não resolveria e não resolveu, obtendo o valor $31(13+10+7+1)$ para o escore --.

\begin{tabular}{c|c|c|c|c|c|c|c|c|c|c|c|c|c|c|c}
\hline & \multicolumn{1}{|c}{ Avaliações KMA das mais recentes para as mais antigas } \\
\hline Avaliações KMA & ++ & +- & -- & ++ & ++ & -- & -+ & ++ & -- & ++ & ++ & ++ & +- & ++ & -- \\
\hline Peso & 15 & 14 & 13 & 12 & 11 & 10 & 9 & 8 & 7 & 6 & 5 & 4 & 3 & 2 & 1
\end{tabular}

Tabela 1: Cenário hipotético de avaliações KMA e seus pesos

O agente utiliza os escores KMA para gerar um índice, chamado índice KMA, que mede a discrepância entre o conhecimento avaliado pelo aluno e o conhecimento demonstrado por ele. O índice KMA reflete o nível corrente da habilidade de monitoramento do conhecimento do aluno, e é calculado pela fórmula do Coeficiente Hamman $(\mathrm{CH})$, como sugerido por [63]. A fórmula do $\mathrm{CH}$ (Fórmula 1) utiliza as incógnitas $a, b, c$ e $d$ que referem-se, respectivamente, aos escores KMA ++, +-, -+ e -. O CH calcula a diferença entre a proporção das avaliações corretas do aluno $(a$ e $d$ ) e a proporção das avaliações incorretas do aluno $(b$ e $c)$.

$\mathrm{CH}=\frac{(\mathrm{a}+\mathrm{d})-(\mathrm{b}+\mathrm{c})}{(\mathrm{a}+\mathrm{d})+(\mathrm{b}+\mathrm{c})}$

$\mathrm{O}$ índice KMA é um número real entre -1 e +1 , no qual o valor -1 indica total imprecisão na habilidade de monitoramento do conhecimento, enquanto que o valor +1 indica total precisão.

Este estudo também classificou o índice KMA em duas categorias: satisfatório e insatisfatório. As categorias são separadas por um valor limiar $(+0,5)$. Valores de índice KMA superior ou igual ao valor limiar expressam um valor de índice KMA satisfatório. A escolha do valor limiar foi realizada a partir de uma avaliação formativa (Ver seção 7.1), e objetivou classificar o índice KMA como satisfatório para valores altos o suficiente para expressarem um desempenho metacognitivo bom e consistente.

\subsection{Mecanismos de funcionamento}

$\mathrm{O}$ agente de treinamento possui dois mecanismos de funcionamento: (1) Fluxo Interno, responsável pelo treinamento metacognitivo; e (2) Ciclo Externo, responsável pela ativação do Fluxo Interno.

O Ciclo Externo é responsável por ativar o Fluxo Interno e é sempre executado antes de o aluno tefitar resolver um novo passo de um problema. Duas estratégias são utilizadas para o Ciclo Externo decidir se o Fluxo Interno é ativado.

A primeira estratégia toma decisões baseadas no nível metacognitivo de monitoramento do conhecimento do aluno, e é utilizada quando o índice KMA corrente do aprendiz é insatisfatório, ou quando ele recém começou o treinamento. Um número real pertencente ao intervalo de valores do índice KMA, entre -1 e +1 , é gerado aleatoriamente utilizando uma função de probabilidade uniforme. 
Caso o valor gerado seja um valor maior ou igual ao índice KMA corrente do aluno, o Fluxo Interno é ativado. Desta forma, quanto maior o índice KMA do aluno, menor a probabilidade de ativação do Fluxo Interno. Assim, a frequência de ativação do Fluxo Interno, responsável pelo treinamento, é adaptada ao nível da habilidade de monitoramento do conhecimento do aprendiz, e a instrução é diminuída a medida que o aluno vai demonstrando competência na habilidade metacognitiva.

A segunda estratégia do Ciclo Externo toma a decisão de ativar o Fluxo Interno de acordo com o conhecimento do aluno no domínio, e é utilizada quando o aluno mantém um índice KMA satisfatório. Evidências encontradas na avaliação formativa (teste-piloto) levaram os autores deste estudo a acreditarem que os alunos precisam refletir mais sobre o seu conhecimento quando os aprendizes nem completamente sabem ou desconhecem como resolver um próximo passo. Estas evidências surgiram de observações visuais dos pesquisadores em conjunto de relatos dos alunos durante a avaliação formativa. As observações e relatos mostraram que muitos alunos usam mais tempo para pensar no seu conhecimento antes de resolver um próximo passo quando o próximo passo necessita de conhecimentos que o aluno nem completamente desconhece e nem completamente domina. O Ciclo Externo utiliza informações fornecidas pelo Modelo de Aluno e pelo sistema especialista do STI. Sabendo que o sistema especialista é capaz de inferir as unidades de conhecimento possíveis de serem aplicadas num próximo passo, o Modelo de Aluno é capaz de fornecer a probabilidade de conhecimento do aluno nestas unidades de conhecimento. Assim, o mecanismo do Ciclo Externo utiliza a probabilidade de domínio do aluno nos conhecimentos possíveis de serem aplicados na resolução do próximo passo, para gerar um índice de relevância do próximo passo. Primeiramente, o mecanismo gera um índice de relevância de cada unidade de conhecimento possível de ser aplicada no próximo passo, chamado iRUC. A fórmula do iRUC (Fórmula 2) utiliza a razão matemática da distância existente entre a probabilidade de conhecimento do aluno na unidade de conhecimento e o valor $0,5(50 \%)$. Uma probabilidade de conhecimento de $50 \%$ indica que o aluno provavelmente não domina nem desconhece totalmente a unidade de conhecimento. $\mathrm{O}$ iRUC é um valor real entre 0 e +1 . Quanto mais próximo de $50 \%$ for a probabilidade de domínio do aluno na unidade de conhecimento, mais próximo de +1 é o valor de iRUC.

iRUC $_{\text {conhacimento }}=1-\frac{\| 0,5-\text { prob }_{\text {conhscinanto }} \mid}{0,5}$
Após gerar o iRUC para cada unidade de conhecimento possível de ser aplicada no próximo passo, o mecanismo gera o índice de relevância do próximo passo (iRPP), este sim, utilizado pela segunda estratégia de ativação do Ciclo Externo para a tomada de decisão de ativação do Fluxo Interno. O iRPP é calculado através da média aritmética simples dos $n$ índices iRUCs gerados, como mostra a Fórmula 3, e também é um valor real entre $0 \mathrm{e}+1$.

$\mathrm{iRPP}=\frac{\sum_{\mathrm{x}=1}^{\mathrm{n}} \mathrm{iRUC}_{\mathrm{x}}}{\mathrm{n}}$

Sabendo o valor do iRPP, o mecanismo de Ciclo Externo gera um valor aleatório, entre 0 e +1 , utilizando uma função de probabilidade uniforme. Caso o valor gerado for um valor menor que o índice iRPP, a segunda estratégia do Ciclo Externo ativa o Fluxo Interno. Quanto maior o índice de relevância do próximo passo, o iRPP, maior a probabilidade de ativação do Fluxo Interno quando a segunda estratégia do Ciclo Externo é utilizada. Desta forma, quando a segunda estratégia do Ciclo Externo é utilizada, a frequência de ativação do Fluxo Interno é adaptada ao conhecimento do aluno no domínio, sendo mais provável que a instrução metacognitiva seja ativada em passos que o aluno necessite refletir mais sobre o seu conhecimento.

O Fluxo Interno é responsável pelo treinamento da habilidade metacognitiva de monitoramento do conhecimento. A Figura 4 apresenta o fluxo de procedimentos e tomadas de decisão do Fluxo Interno. Os retângulos representam as ações do sistema (escuros) ou do aluno (brancos). Os losangos representam as tomadas de decisão do sistema.

Segundo a Figura 4, se inicialmente, o índice KMA é insatisfatório, o mecanismo seleciona um prompt metacognitivo que encoraja o aluno a refletir se ele tem conhecimento para resolver o próximo passo do problema. O mecanismo aguarda o aluno entrar com uma solução para o próximo passo. Caso o aluno tenha sido muito reativo, ou seja, se o aluno entrou com sua solução muito rapidamente, uma mensagem de feedback imediato é entregue ao aluno, indicando o comportamento inadequado. Como indica o fluxo, antes de entrar com uma solução para o passo, o aluno deve avaliar se ele tem conhecimento para resolver o próximo passo escolhendo a opção "SIM" ou "NÃO". Em seguida, o mecanismo compara a avaliação do aluno para o próximo passo com o desempenho do aluno no mesmo passo e atualiza um dos escores KMA e, consequentemente, o índice KMA. Após o aluno avaliar seu conhecimento, o mecanismo pode escolher, aleatoriamente, entregar uma atividade de 
self-explanation, no qual o aluno preenche um formulário descrevendo as razões relacionadas à sua avaliação recente do seu conhecimento. Além disso, o mecanismo pode fornecer (escolha aleatória) um feedback informando o aluno sobre o nível corrente da sua habilidade de monitorar seu conhecimento, explicando também a importância dessa habilidade metacognitiva em sua aprendizagem.

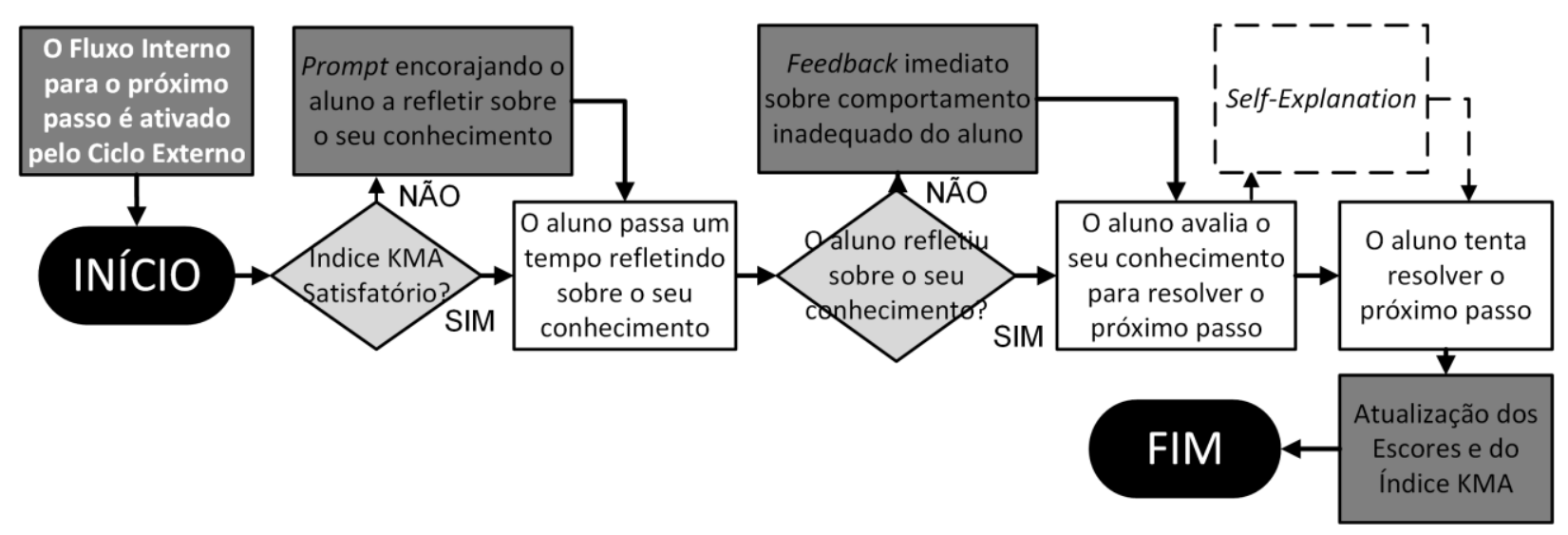

Figura 4: Fluxo de procedimentos e tomadas de decisão do Fluxo Interno

Um cuidado importante do treinamento metacognitivo proposto tem relação com a atualização do índice metacognitivo corrente do estudante. Como o índice KMA é gerado pelo mecanismo de Fluxo Interno, caso o aluno tenha um bom índice metacognitivo e um bom desempenho no domínio, poderia ocorrer de o mecanismo de Ciclo Externo demorar muitos passos até ativar novamente o Fluxo Interno. Na avaliação formativa (teste-piloto), ocorreram casos do Fluxo Interno não ter sido ativado após mais de 30 passos do aluno. Este comportamento comprometeria a manutenção do índice metacognitivo corrente do aluno. Assim, para a avaliação somativa (Ver seção 7.2), o treinamento foi ajustado para que o Ciclo Externo forçasse a ativação do Fluxo Interno quando este não fosse ativado por mais de 10 passos do aluno, garan- tindo a atualização do índice metacognitivo.

\subsection{Prompts metacognitivos}

Os prompts metacognitivos são mensagens de texto que são ativadas pelo Fluxo Interno e encorajam os alunos a refletirem sobre seu conhecimento. As mensagens de prompts adotam as estratégias descritas em [11, 56, $34,18]$, que buscam encorajar o aluno a: (1) identificar o que o problema está pedindo; (2) dedicar algum tempo para refletir sobre o seu conhecimento antes de entrar com uma solução para o próximo passo do problema; e (3) refletir sobre algum problema similar que já foi resolvido por ele anteriormente.

\begin{tabular}{|c|c|c|}
\hline Nível & Estratégia & Exemplo de Prompt Metacognitivo \\
\hline 1 & $\begin{array}{l}\text { Encorajar o aluno a refletir sobre } \\
\text { o seu conhecimento, direcionando o } \\
\text { foco da reflexão ao enunciado do } \\
\text { problema. }\end{array}$ & $\begin{array}{l}\text { O agente pedagógico exibe a mensagem "Passe um tempo } \\
\text { lendo e identificando as partes da tarefa, para que } \\
\text { você consiga identificar se possui conhecimento para } \\
\text { entrar com um novo passo de resolução.". }\end{array}$ \\
\hline 2 & $\begin{array}{l}\text { Encorajar o aluno a refletir sobre } \\
\text { o seu conhecimento, direcionando o } \\
\text { foco da reflexão a algum conheci- } \\
\text { mento que o aluno já tenha demons- } \\
\text { trado algum domínio necessário } \\
\text { para resolver o próximo passo no } \\
\text { problema atual. }\end{array}$ & $\begin{array}{l}\text { O agente pedagógico exibe a mensagem: "Você já de- } \\
\text { monstrou ter algum conhecimento para dar um novo } \\
\text { passo correto de resolução. Passe um tempo lendo a } \\
\text { tarefa e refletindo sobre seu conhecimento.". }\end{array}$ \\
\hline 3 & $\begin{array}{l}\text { Encorajar o aluno a refletir sobre } \\
\text { o seu conhecimento, direcionando o } \\
\text { foco da reflexão a algum passo de } \\
\text { tarefa similar anteriormente re- } \\
\text { solvido. }\end{array}$ & $\begin{array}{l}\text { O agente pedagógico exibe a mensagem "Você já resol- } \\
\text { veu anteriormente um passo similar em que utilizou } \\
\text { conhecimento necessário para dar um novo passo na } \\
\text { tarefa corrente. Passe um tempo lendo a tarefa e } \\
\text { refletindo sobre seu conhecimento.". }\end{array}$ \\
\hline 4 & Encorajar o aluno a refletir sobre & O agente pedagógico exibe um passo similar resolvido \\
\hline
\end{tabular}






anteriormente pelo aluno e a mensagem "Veja o passo similar que você já resolveu antes. Neste passo similar, você utilizou conhecimento que poderia utilizar para resolver um novo passo da tarefa corrente. Passe um tempo refletindo sobre seu conhecimento." .

Tabela 2: Níveis de prompts metacognitivos

As mensagens de prompts foram agrupadas em níveis, como apresentado na Tabela 2. O primeiro nível encoraja o aluno a refletir sobre o seu conhecimento a partir do próprio enunciado da tarefa, orientando o estudante a passar um tempo refletindo sobre o seu conhecimento para resolver o próximo passo. O segundo nível encoraja o aprendiz a refletir sobre o seu conhecimento, direcionando o foco a algum conhecimento necessário para dar um novo passo de resolução e que o aluno já tenha demonstrado algum domínio. O terceiro nível encoraja o aluno a refletir sobre o seu conhecimento, direcionando o foco de atenção do aprendiz para um passo de problema que ele tenha resolvido anteriormente e no qual ele empregou algum conhecimento que poderá ser aplicado no próximo passo do problema. Esta estratégia encoraja o aluno a pensar em algum problema relacionado, utilizando-o como modelo. O quarto nível utiliza a mesma estratégia do nível anterior, porém, mostra explicitamente ao aluno (na interface gráfica do STI) o problema e o respectivo passo que ele resolveu anteriormente em que utilizou um conhecimento que poderá ser empregado novamente para resolver o próximo passo do problema atual. Quanto mais próximo do nível 4, mais específico é o objeto de reflexão.

O segundo nível de prompt utiliza as probabilidades de conhecimento do aluno nas operações e conceitos matemáticos, inferidas pelo Modelo de Aluno do STI. O segundo, terceiro e quarto níveis utilizam a informação relativa às unidades de conhecimento possíveis de serem empregadas no próximo passo, inferidas pelo sistema especialista do STI. O terceiro e quarto níveis também utilizam o histórico de resolução de passos de tarefas, mantido pelo Modelo de Aluno.

A Tabela 2 apresenta exemplos de mensagens de prompts utilizadas neste estudo. Para que as mensagens não se tornassem repetitivas para o aluno, foram utilizadas 65 mensagens distribuídas nos quatro níveis de pro- mpts. Estas mensagens foram todas validadas pelos professores de Matemática das turmas onde foi realizada a avaliação somativa. Os professores avaliaram se os termos utilizados nas mensagens, relacionados ao domínio de álgebra, eram familiares aos termos utilizados em sala de aula. Também validaram a clareza das mensagens para a compreensão dos alunos.

A abordagem utilizada para selecionar os prompts que são entregues ao aluno foi baseada em uma política chamada tutoria contingente, originada em estudos sobre tutores humanos. Estes estudos encontraram que tutores humanos efetivos selecionam dicas de acordo com o desempenho recente dos aprendizes [32]. Sabendo disso, a entrega dos prompts metacognitivos é adaptada ao nível metacognitivo de monitoramento do conhecimento do aluno.

Um prompt é apenas selecionado quando o índice KMA do aluno é insatisfatório, como mostra o fluxo da Figura 4. Além disso, quando o prompt metacognitivo é entregue, o nível de prompt é selecionado de acordo com o índice KMA do aluno. Quanto menor o índice metacognitivo, mais alto o nível de prompt selecionado (mais próximo do nível 4), ou seja, mais específico é o objeto de reflexão do prompt.

subKMAins $=\frac{\operatorname{limiar}-(-1)}{n}$

O mecanismo de seleção de prompts divide o intervalo de valores relativos ao índice KMA insatisfatório, entre -1 e um valor limiar $(+0,5)$, em $n$ subintervalos de valores reais, cuja amplitude dos subintervalos é definida pela fórmula 4. A letra $n$ corresponde à quantidade de níveis de prompts, que neste trabalho são quatro. 


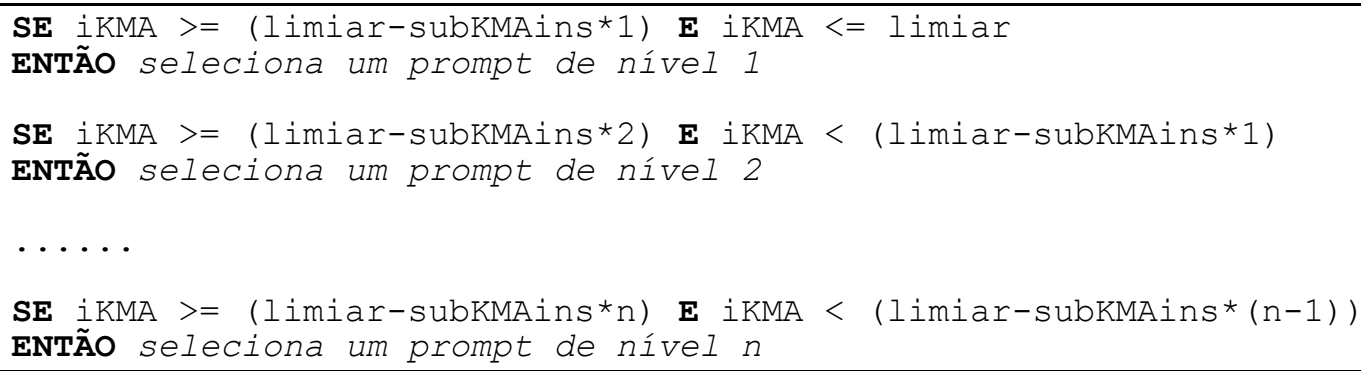

Figura 5 : Regras de seleção dos níveis de prompts

O mecanismo de seleção dos níveis de prompts, apresentado na Figura 5, pode ser representado por regras do tipo $S E . . . E N T \tilde{A} O$. O mecanismo verifica em qual subintervalo de KMA insatisfatório pertence o índice KMA corrente do aluno e utiliza esta informação para selecionar o nível de prompt.

$\mathrm{O}$ índice KMA corrente do aluno é representado pela variável $i K M A$. A primeira regra seleciona o primeiro nível de prompts metacognitivos (nível 1), quando o índice KMA do aluno é um valor pertencente ao subintervalo de KMA insatisfatório com os maiores valores (próximo do valor limiar). A última regra seleciona o último nível de prompts (nivel 4), quando o índice KMA do aluno é um valor pertencente ao subintervalo de valo-

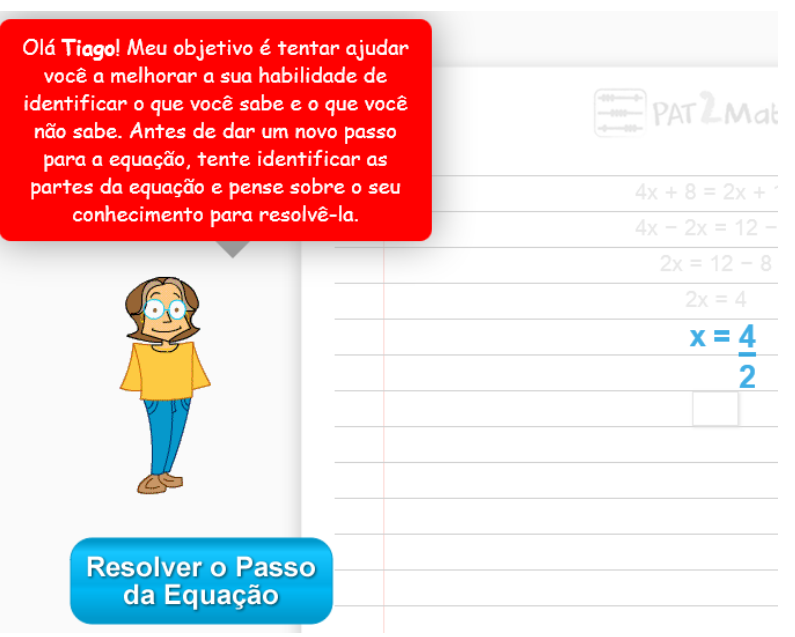

res mais baixos de KMA insatisfatório.

Quando um nível de prompt é selecionado, a mensagem utilizada pelo agente é escolhida aleatoriamente utilizando uma função de probabilidade uniforme.

\subsection{Implementação do agente e integração com um STI}

$\mathrm{O}$ agente pedagógico foi implementado como um agente pedagógico animado (APA) (ver Seção 4). O APA utilizado neste estudo foi implementado como um personagem feminino $2 \mathrm{D}$, de corpo inteiro, que aparece na interface gráfica todo o tempo em que o aluno está no sistema. Possui expressões faciais relacionadas à fala, espera e outras expressões como acenos e piscadas.

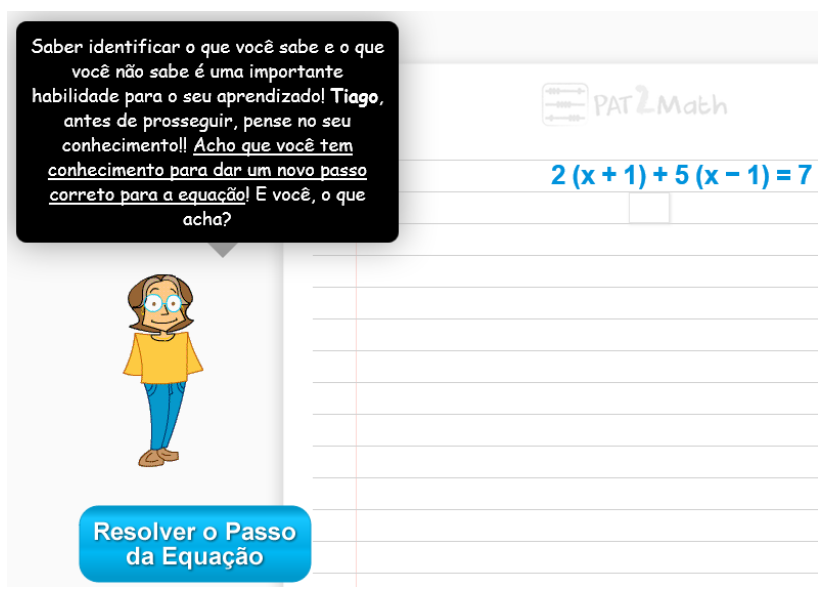



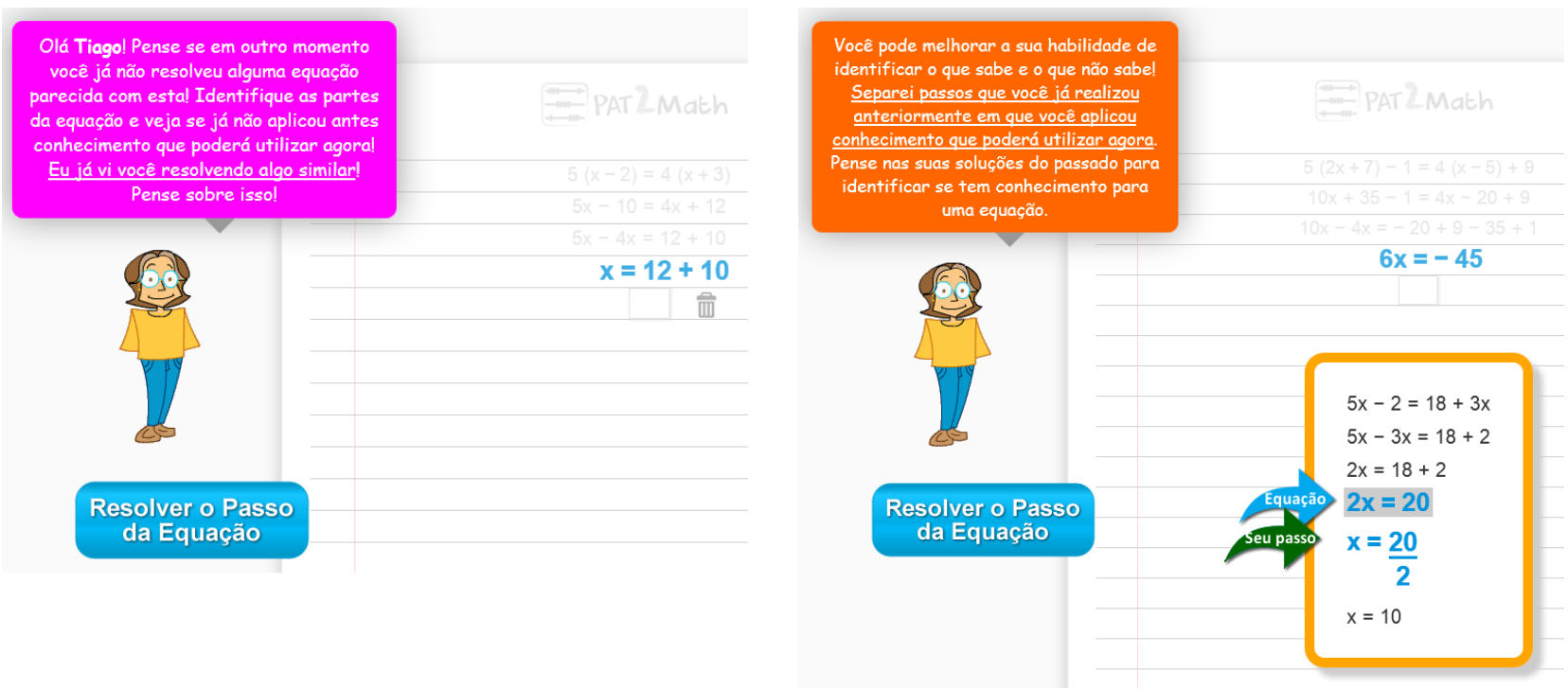

Figura 6: O APA encorajando o aluno a refletir sobre seu conhecimento: (a) a partir do que o problema está pedindo (prompt de nível 1); (b) a partir de algum conhecimento já demonstrado pelo aluno (prompt de nível 2); (c) a partir de algum passo similar já resolvido pelo aluno (prompt de nível 3); (d) a partir de algum passo similar já resolvido pelo aluno, mostrado na interface do STI (prompt de nível 4).

Os conteúdos relativos aos prompts metacognitivos, feedbacks metacognitivos e mensagens explicando a importância da aplicação da habilidade metacognitiva durante o aprendizado, são entregues através de balões de fala do APA. A figura 6 mostra o APA integrado ao STI de álgebra PAT2Math. Cada imagem da figura mostra o APA entregando um tipo de prompt metacognitivo.

Em relação à atividade de Self-Explanation, uma das atividades possíveis de serem entregues pelo mecanismo de Fluxo Interno, o aluno preenche um formulário em que escreve, com suas próprias palavras, os motivos que o levaram à determinada avaliação do próprio conhecimento. O presente estudo não realizou nenhum tratamento ou avaliação sobre este conteúdo gerado pelo aluno. Ele tem apenas o objetivo de encorajar o aluno a refletir sobre sua avaliação metacognitiva, mas não é realizada nenhuma verificação do conteúdo a fim de observar se a reflexão foi realmente realizada pelo aprendiz.

Como o modelo de agente metacognitivo foi implementado e integrado ao PAT2Math, um STI do tipo stepbased que atua no domínio de equações algébricas, é necessário que os conceitos sobre problemas e passos de problemas sejam contextualizados. Um problema, no domínio de resolução de equações algébricas, é uma equação que é apresentada na interface gráfica do STI, para ser resolvida pelo aluno. Consequentemente, um passo de tarefa é um passo para resolver a equação. $\mathrm{O}$ sistema poderia apresentar o seguinte problema ao aluno: $5 x-3=7$. Espera-se que o aluno reflita sobre este problema e sobre o seu conhecimento para entrar com um passo de resolução. Então, o aluno poderia entrar com o seguinte passo: $5 x=7+3$. Este passo de solução, que também é uma equação e não é a solução final da equação anterior, passa a ser um novo problema e um novo objeto de reflexão do aluno para dar um novo passo. Em seguida, o aluno poderia entrar com o passo $5 x=10$, que passa a ser o novo problema, ou seja, o novo objeto de reflexão para o aprendiz dar um novo passo. Este processo continua até que o aluno entre com o passo final da solução, que na equação de exemplo, é $x=2$.

Para o presente trabalho, o PAT2Math considera apenas equações algébricas de $1^{\circ}$ grau com uma incógnita, pois o Modelo de Aluno atual do PAT2Math não infere unidades de conhecimento relativas a equações de $2^{\circ}$ grau. A cada problema (equação) que é apresentado ao aluno ou antes de cada passo de resolução do aluno, o mecanismo de Ciclo Externo, descrito na seção 6.2, é executado. A cada execução do Ciclo Externo, o mecanismo de Fluxo Interno, responsável pelo treinamento metacognitivo, é ativado ou não.

\section{Avaliação}

A avaliação do sistema ocorreu em duas etapas: a primeira formativa e a segunda somativa [44]. A avaliação formativa buscou avaliar a usabilidade e o funcionamento do sistema, além do comportamento dos alunos durante a interação com o sistema. A partir das observações na avaliação formativa, foram realizados alguns ajustes no sistema. A avaliação somativa, por sua vez, buscou verificar se o treinamento adaptativo da habilidade de monitoramento do conhecimento em sistemas tuto- 
res leva a uma melhora dessa habilidade e da aprendizagem dos alunos. As duas etapas da avaliação são descritas com mais detalhes nas próximas seções.

\subsection{Avaliação formativa}

Algumas decisões relacionadas ao treinamento, como o valor limiar $(+0,5)$ que separa as categorias de índice KMA satisfatório de insatisfatório, foram tomadas após observações realizadas em sessões de uma avaliação formativa (teste-piloto). O objetivo do teste-piloto foi avaliar o método utilizado no estudo de avaliação (descrito na próxima sessão), bem como aspectos operacionais do treinamento e de usabilidade do sistema. Foram realizadas três sessões com um grupo de 17 alunos de uma escola particular da região do Vale dos Sinos, no Rio Grande do Sul. Estes alunos não participaram da avaliação somativa descrita na Seção 7.2. Os alunos foram divididos aleatoriamente em dois grupos: controle e experimental. Cada sessão teve duração de 50 minutos, com intervalo de uma semana entre as sessões. Em duas sessões, os alunos utilizaram o PAT2Math com o agente pedagógico animado integrado. Na terceira sessão ocorreu um pós-teste, em que os alunos realizaram um teste de desempenho e um instrumento de avaliação metacognitiva, em papel e caneta. Foram observadas questões como usabilidade e funcionamento do treinamento fornecido pelo sistema, além do comportamento dos alunos durante as sessões. Sobre o treinamento, foram observados alguns aspectos afetados por parâmetros do treinamento, com o objetivo de adequar estes parâmetros. Um exemplo é o valor limiar que separa a avaliação do índice KMA como satisfatório ou insatisfatório, procurando encontrar um valor limiar alto o suficiente para expressar um índice KMA satisfatório e consistente. Outro exemplo de parâmetro avaliado foi o tempo necessário para o aluno conseguir ler toda a mensagem de prompt metacognitivo que lhe é entregue, sem que receba um feedback indicando um comportamento inadequado, de que foi muito reativo não lendo a mensagem de reflexão do agente pedagógico animado. Para este último parâmetro, por exemplo, a avaliação formativa permitiu encontrar um tempo mínimo necessário para a leitura dos prompts, para a maioria dos alunos, de 10 milissegundos por caractere.

\subsection{Avaliação somativa}

O objetivo da avaliação somativa é verificar o efeito de instruir explicitamente os alunos, em um ambiente computacional de aprendizagem, a refletirem sobre o seu conhecimento quando o conteúdo e a frequência de intervenções do treinamento são adaptados ao nível corrente da habilidade de monitoramento do conhecimento dos alunos, aos conhecimentos dos estudantes no domínio do problema e ao histórico de resolução de problemas dos aprendizes.
As próximas seções descrevem as hipóteses e questões de pesquisa levantadas, além do método utilizado na avaliação somativa, os participantes envolvidos e os materiais coletados.

\subsubsection{Hipóteses e questões de pesquisa}

O estudo objetiva responder as seguintes questões de pesquisa: (1) o treinamento adaptativo melhora a habilidade de monitoramento do conhecimento dos alunos?; (2) o treinamento adaptativo melhora o conhecimento dos alunos no domínio?; (3) é possível encontrar uma correlação entre o nível da habilidade de monitoramento do conhecimento dos alunos com seu desempenho no domínio quando eles recebem o treinamento metacognitivo adaptativo?

A hipótese dos autores deste estudo é que o treinamento adaptativo efetivamente melhora a habilidade de monitoramento do conhecimento, porque encoraja os alunos a refletirem sobre seu conhecimento, fazendo-os agir menos reativamente, e também porque os conscientiza da importância desta habilidade metacognitiva em seus estudos. Além disso, a frequência e o conteúdo das intervenções do treinamento são adaptados à habilidade metacognitiva corrente de monitoramento do conhecimento dos estudantes, seus conhecimentos no domínio dos problemas e seus históricos de resolução de problemas. Os benefícios da característica adaptativa da instrução em ambientes computacionais já foi encontrada por [49], mas não na instrução específica da habilidade de monitoramento do conhecimento. No contexto da instrução em ambientes computacionais de aprendizagem, pesquisas existentes usaram mensagens para levar o aluno a refletir sobre seu próprio conhecimento, além de tentarem desenvolver outras habilidades metacognitivas. Além disso, estes trabalhos não investigaram os efeitos isolados da reflexão do aprendiz sobre seu conhecimento para uma melhora da habilidade metacognitiva específica de monitoramento do conhecimento. Estes trabalhos também não adaptaram a instrução ao conhecimento e desempenho do aprendiz.

Outra hipótese do presente trabalho é que o treinamento metacognitivo melhora a aprendizagem, pois as ações da instrução levam o aluno a ser menos reativo e a ter consciência das suas lacunas de aprendizagem. Esta consciência pode levar os alunos a suprirem seus conhecimentos deficitários, buscando ajuda em livros, colegas ou professores. Sabendo disso, também é levantada a hipótese de que pode ser encontrada uma correlação entre a habilidade metacognitiva de monitoramento do conhecimento e o desempenho dos alunos no domínio quando recebem o treinamento metacognitivo proposto neste trabalho. Esta correlação já foi encontrada em sala de aula, como descrita em [63], mas ainda não na instrução em ambientes computacionais de aprendizagem, como 
em STIs.

\subsubsection{Método e participantes}

Uma avaliação experimental seguindo um design pré e pós-testes com grupo de controle e experimental foi realizada em três turmas de $8^{\circ}$ Ano do Ensino Fundamental e uma turma de $7^{\circ}$ Ano do Ensino Fundamental em quatro escolas privadas da região do Vale dos Sinos, no Rio Grande do Sul. O estudo teve a participação de 107 alunos, com idade entre 12 e 14 anos, que foram aleatoriamente atribuídos a dois grupos: experimental e controle. No entanto, foi possível considerar apenas os dados de 63 alunos que retornaram o termo de consentimento assinado, como requerido pelo Comitê Brasileiro de Ética na Pesquisa (CONEP), e que completaram todos os testes de avaliação atribuídos. 34 alunos foram atribuídos ao grupo de controle (44\% de meninos e $56 \%$ de meninas) e 29 alunos foram atribuídos ao grupo experimental $(55 \%$ de meninos e $45 \%$ de meninas).

O experimento foi composto de um total de seis a sete sessões. Na primeira sessão, os alunos receberam o treinamento metacognitivo no sistema tutor PAT2Math sem o agente. Na segunda sessão, de pré-teste, os alunos retornaram o termo de consentimento (recebido na sessão anterior) assinado por seus pais e realizaram um teste de desempenho e um instrumento de avaliação metacognitiva. Nas sessões seguintes (quatro sessões com duas turmas e apenas três sessões com as outras duas turmas, devido a restrições de calendário das escolas), os estudantes resolveram equações usando duas versões diferentes do PAT2Math com o agente integrado. Na condição experimental o agente pedagógico animado entregou a instrução metacognitiva adaptativa. Na condição de controle, o agente foi modificado para não entregar ações metacognitivas, e apenas fornecer dicas relacionadas ao domínio, que também foram entregues pelo agente na condição experimental. Na última sessão (pós-teste), os alunos completaram um teste de desempenho e um instrumento de avaliação metacognitiva. Cada sessão durou 50 minutos e todas as sessões tiveram intervalo de uma semana.

\subsubsection{Materiais}

Nas sessões de pré-teste e pós-teste, foram coletadas as notas de desempenho dos alunos que avaliaram a aprendizagem. Os instrumentos de avaliação metacognitiva, realizados igualmente nas seções de pré-teste e pósteste, coletaram os índices metacognitivos (índice KMA) que avaliaram a habilidade de monitoramento do conhecimento dos aprendizes. Na sessão de pré-teste, os alunos receberam uma folha de papel contendo dez equações de álgebra. Para cada equação, os estudantes avaliaram se tinham conhecimento para resolvê-la (instrumento de avaliação metacognitiva). Os alunos retornaram este papel ao professor que, então, entregou outra folha de papel contendo as mesmas equações da folha anterior, mas desta vez os alunos deveriam tentar resolver os problemas (teste de desempenho). O mesmo procedimento foi aplicado na sessão de pós-teste, porém com equações diferentes e com o mesmo nível de dificuldade da sessão de pré-teste. A comparação das avaliações metacognitivas com o desempenho nos testes permitiu a definição dos escores KMA e, consequentemente, a definição do índice KMA de cada aluno, tanto na seção de pré-teste quanto na seção de pós-teste. A avaliação do desempenho dos estudantes nos testes resultou em escores (notas) de desempenho (números inteiros entre 0 e 10) para cada um, tanto no pré-teste quanto no pós-teste.

\section{Resultados}

Os resultados dessa seção compreendem apenas a análise da avaliação somativa. Para comparar o desempenho da habilidade metacognitiva de monitoramento do conhecimento e o desempenho no domínio entre as condições experimental e controle, foram realizados testes $t$ de Student. A confiabilidade dos dados foi testada através de testes Ryan-joiner para avaliar a normalidade das amostras e testes de Levene para avaliar a homogeneidade das variâncias. Testes de correlação utilizando o coeficiente de Pearson foram realizados para a verificar a correlação existente entre o índice KMA e as notas no domínio.

\subsection{Monitoramento do conhecimento}

Um teste $t$ de amostras independentes $(\alpha=.05)$ comparando a média do índice KMA do grupo experimental $(M=.800, D P=.251)$ com a média do grupo de controle $(M=.605, D P=.413)$, ambos no pós-teste, encontrou uma média significativamente superior $(t(61)=2.214, p$ $=.015)$ para o grupo experimental. Um segundo teste $t$ de amostras independentes comparou os ganhos de índice KMA (diferença entre os índices no pós-teste e no préteste) dos grupos. Um resultado estatístico marginalmente significativo $(t(61)=1.588, p=.059)$ foi encontrado, indicando que os ganhos de índice KMA no grupo experimental $(M=.231, D P=.373)$ foram superiores aos ganhos no grupo de controle $(M=.061, D P=.463)$. Um terceiro teste $t$ de amostras pareadas comparou os índices KMA entre o pós-teste e o pré-teste dentro de cada grupo e não encontrou diferença estatisticamente significativa $(t(33)=.766, p=.225)$ entre a média do índice KMA no pós-teste $(M=.605, D P=.413)$ e a média do mesmo índice no pré-teste $(M=.544, D P=.325)$ no grupo de controle. No entanto, uma média significativamente superior $(t(28)=3.333, p<.01)$ foi encontrada no pós-teste $(M=.800, D P=.251)$ quando comparado ao pré-teste $(M$ $=.569, D P=.381)$ no grupo experimental. 


\subsection{Desempenho no domínio}

Um teste $t$ de amostras independentes $(\alpha=.05)$ comparou as notas dos estudantes em ambos os grupos no pós-teste. Uma média superior $(t(61)=2.327, p=0.012)$ foi encontrada nas notas do grupo experimental $(M=$ $8.621, D P=1.741)$ quando comparada ao grupo de controle $(M=7.441, D P=2.205)$. Um segundo teste $t$ de amostras independentes comparou os ganhos de notas (diferença entre as notas no pós-teste e as notas no préteste) dos grupos. A média dos ganhos no grupo experimental $(M=2.414, D P=2.147)$ foi superior que a média dos ganhos no grupo de controle $(M=1.941, D P=$ $1.825)$, mas esta diferença não foi estatisticamente significativa $(t(61)=.945, p=.174)$. Um terceiro teste $t$, de amostras pareadas, comparou as notas entre o pós-teste e o pré-teste dentro de cada grupo. Uma média significativamente superior foi encontrada tanto na condição experimental $(t(28)=6.055, p<.001)$ quanto na condição de controle $(t(33)=6.203, p<.001)$.

\subsection{Correlação entre os desempenhos meta- cognitivo e de domínio}

Resultados de testes de correlação utilizando o coeficiente de Pearson $(\alpha=.05)$ encontrou uma correlação positiva, estatisticamente significativa, entre o índice KMA e as notas dos alunos no domínio na condição experimental (Tabela 3). No primeiro teste, relativo aos dados coletados no pré-teste, ambas as condições apresentaram uma correlação positiva moderada. No segundo teste, relativo aos dados coletados no pós-teste, uma forte correlação positiva foi encontrada no grupo experimental e uma fraca correlação positiva foi encontrada no grupo de controle. No terceiro teste, relativo aos ganhos, foi encontrada uma correlação positiva moderada no grupo experimental e uma fraca correlação positiva no grupo de controle. No entanto, na condição de controle, com um valor de $p$ marginal no segundo teste e um valor de $p$ alto no terceiro teste, não há garantias estatísticas para evidenciar uma fraca correlação positiva no grupo de controle nestes testes. Já os valores de $p$ encontrados no grupo experimental são fortes para evidenciar a boa correlação positiva.

\begin{tabular}{c|l|c|c|c|c}
\hline Teste & Correlação testada & & $\begin{array}{c}\text { Controle } \\
\boldsymbol{r}(\boldsymbol{p})\end{array}$ & $\begin{array}{c}\text { Experimental } \\
\boldsymbol{r}(\boldsymbol{p})\end{array}$ \\
\hline 1 & $\begin{array}{l}\text { Índice KMA (pré-teste) X Notas no Domínio (pré- } \\
\text { teste) }\end{array}$ & $+.45 \quad(.006)$ & $+.60 \quad(.001)$ \\
\hline 2 & $\begin{array}{l}\text { Índice KMA (pós-teste) X Notas no Domínio (pós- } \\
\text { teste) }\end{array}$ & $+.29(.090)$ & $+.92 \quad(.000)$ \\
\hline 3 & Ganhos de Índice KMA X Ganhos de Notas no Domínio & $+.13 \quad(.450)$ & $+.65 \quad(.000)$ \\
\hline
\end{tabular}

Tabela 3: Correlação entre o índice KMA e as notas de desempenho no domínio

\section{Discussão}

Os resultados dos testes estatísticos apresentaram evidências que corroboram com a hipótese de que o treinamento fornecido pelo agente pode melhorar a habilidade dos alunos de identificarem o que sabem e o que não sabem para resolver um problema. Todos os testes estatísticos indicaram que os alunos na condição experimental, que receberam o treinamento metacognitivo integrado ao sistema tutor algébrico, tiveram índices metacognitivos da habilidade de monitoramento do conhecimento superiores aos alunos que participaram na condição de controle, que não receberam o treinamento metacognitivo do sistema.

$\mathrm{O}$ estudo também encontrou evidências que apoiam a hipótese de que a instrução metacognitiva do agente pode melhorar o desempenho dos alunos no domínio, embora os resultados estatísticos não terem sido tão sólidos. Apesar do estudo ter encontrado resultados sólidos para a condição experimental na comparação das notas no domínio na etapa de pós-teste, o resultado relativo à comparação dos ganhos de desempenho foi apenas marginal no grupo que recebeu a instrução metacognitiva. Além disso, a comparação entre o pós-teste e o pré-teste apresentou diferenças significativas em ambos os grupos.

Os autores deste estudo acreditam que os resultados poderiam ter sido ainda melhores no desempenho metacognitivo e mais significativos no desempenho no domínio se os alunos recebessem o treinamento em um período maior de tempo. O motivo dessa crença é que um dos princípios fundamentais para se alcançar os objetivos em uma instrução metacognitiva é que o treinamento das habilidades metacognitivas deve ser prolongado [43]. Os alunos participaram de três ou quatro sessões de uso do 
sistema tutor. A quantidade de sessões foi reduzida devido a restrições de agendamento de horários das escolas.

O estudo também encontrou evidências de uma forte correlação positiva entre a habilidade de monitoramento do conhecimento e o desempenho no domínio com os alunos que receberam o treinamento do agente. A análise de correlação não infere causalidade, ou seja, não é possível concluir que uma variável levou a outra, mas indica o nível de relacionamento quando estas variáveis são observadas nas condições de avaliação. Estas evidências estão de acordo com resultados encontrados em sala de aula, como descrito por [63]. No entanto, estes resultados ainda não haviam sido verificados na instrução em ambientes computacionais e, mais especificamente, em sistemas tutores inteligentes.

\section{Conclusões}

O presente estudo investigou os efeitos de um treinamento adaptativo da habilidade de monitoramento do conhecimento em sistemas tutores inteligentes. Foi desenvolvido um agente pedagógico animado que treina o monitoramento do conhecimento em sistemas tutores inteligentes do tipo step-based. O agente encoraja o aluno a refletir sobre seu conhecimento durante o processo de resolução de problemas e adapta o conteúdo e a frequência de intervenções do treinamento ao nível corrente da habilidade de monitoramento do conhecimento do aluno, ao seu conhecimento no domínio e ao seu histórico de resolução de problemas.

Outras pesquisas envolvendo treinamento de habilidades metacognitivas em sistemas computacionais de aprendizagem encorajaram os aprendizes a refletir sobre o seu conhecimento em determinado momento da instrução. No entanto, eles treinaram várias habilidades metacognitivas em conjunto, assim como não buscaram adaptar a etapa do treinamento em que encorajou o aluno a identificar o seu conhecimento a características do aprendiz. O presente estudo investigou os efeitos específicos de uma instrução adaptativa entregue por sistemas computacionais de aprendizagem que encoraja o aluno a refletir sobre o seu conhecimento para promover a habilidade metacognitiva de monitoramento do conhecimento.

No estudo de avaliação, o agente pedagógico animado foi integrado ao sistema PAT2Math, um STI do tipo stepbased que dá assistência ao aluno durante a resolução de equações de primeiro grau. Os resultados sugerem que o treinamento adaptativo da habilidade de monitoramento do conhecimento, que considera a habilidade corrente do aluno de monitorar seu conhecimento, seu desempenho no domínio e histórico de resolução de problemas, pode melhorar a habilidade metacognitiva dos alunos de identificarem seu conhecimento e também a aprendizagem. Uma correlação positiva entre a habilidade metacognitiva e o desempenho no domínio também foi encontrada.

Como estudos futuros, pretende-se investigar possibilidades de aperfeiçoamento do treinamento e do mecanismo de inferência da habilidade metacognitiva de monitoramento do conhecimento considerando outras características do aluno, como o excesso de confiança e a falta de engajamento nas atividades do treinamento. $\mathrm{O}$ presente trabalho utilizou o instrumento KMA, definido por [63], que infere o nível metacognitivo do aluno comparando a estimativa do aprendiz sobre seu conhecimento para resolver um problema com o seu desempenho na solução do mesmo problema. Tanto o instrumento KMA quanto o treinamento não consideram, por exemplo, um viés cognitivo conhecido como excesso de confiança (overconfidence), em que a confiança de uma pessoa em seus julgamentos excede a precisão destes julgamentos. Durante as sessões de uso do sistema tutor no estudo de avaliação, o experimentador observou que alguns alunos aparentavam estarem com excesso de confiança em seus julgamentos. Este viés não é considerado no treinamento e na avaliação metacognitiva do instrumento KMA, o que pode prejudicar a precisão da inferência do nível metacognitivo do aluno.

\section{Referências}

[1] A. Desoete, H. Roeyers, A. de Clercq. Can Offline Metacognition Enhance Mathematical Problem Solving? Journal of Educational Psychology. Washington, 2003.

[2] A. H. Schoenfeld. What's all the Fuss About Metacognition? In Cognitive Science and Mathematics Education. Hillsdale, NJ, 1987.

[3] B. J. Reiser. Why scaffolding should sometimes make tasks more difficult for learners. In Proceedings of Conference on Computer Support for Colaborative Learning. Boulder, Colorado, 2002.

[4] B. J. Zimmerman. A Social Cognitive View of Self-Regulated Academic Learning. Journal of Educational Psychology. New York, NY, 1989.

[5] B. J. Zimmerman. Investigating self-regulated and motivation: Historical background, methodological development, and future prospects. American Educational Research Journal. Los Angeles, 2008.

[6] B. Kramarski, T. Michalsky. Student and Teacher Perspectives on IMPROVE SelfRegulation Prompts in Web-Based Learning. In International Handbook of Metacognition and Learning. NY, 2013. 
[7] B. Kramarski, Z. R. Mevarech, M. Arami. The effects of Metacognitive Instruction on Solving Mathematical Authentic Tasks. Educational Studies in Mathematics. Netherlands, 2002.

[8] B. P. Woolf, J. Reid, N. Stillings, M. Bruno, D. Murray, P. Reese, A. Peterfreund, K. Rath. A General Platform for Inquiry Learning. In International Conference of Intelligent Tutoring Systems. NY, 2002.

[9] B. P. Woolf. Building Intelligent Interactive Tutors: Student-centered strategies for revolutionizing e-learning. Burlington, 2009.

[10] B. S. Bloom. The 2 sigma problem: the search for methods of group instruction as effective as one-to-one tutoring. Educational Researcher. New Orleans, LA, 1984.

[11] C. A. Gama. Integrating Metacognition Instruction in Interactive Learning Environments. Thesis (PhD). University of Sussex, Brighton, 2004.

[12] C. A. Gama. Integrating Metacognition Instruction in Interactive Learning Environments. Thesis (PhD). University of Sussex, Brighton, 2004.

[13] D. Boud, N. Falchikov. Quantitative Studies of Student Self-Assessment in Higher Education: a Critical Analysis of Findings. Higher Education. New York, 1989.

[14] D. Gürer. The use of distributed agents in intelligent tutoring. In ITS Workshop on Pedagogical Agents. San Antonio, Texas, 1998.

[15] E. A. Davis. Prompting Middle School Science Students for Productive Reflection: Generic and Directed Prompts. Journal of the Learning Sciences. Mahwah, NJ, 2003.

[16] E. P. Pimentel, N. Omar, V. F. de França. Um modelo para Incorporação de Automonitoramento da Aprendizagem em STI. Revista Brasileira de Informática na Educação. Porto Alegre, 2005.

[17] E. W. Bocca. Modelagem e Implementação da Interface para Apresentação de Comportamentos Animados e Emotivos de um Agente Pedagógico Animado. Dissertação (Mestrado em Ciência da Computação) - Instituto de Informática, UFRGS. Porto Alegre, 2003.

[18] G. Polya. How to Solve It. Princeton University Press, Garden City, NY, 1957.

[19] H. J. HARTMAN. Metacognition in teaching and learning: An introduction. Instructional Science, Netherlands, 1998.
[20] H. J. Hartmann. Teaching Metacognitively. In Metacognition in Learning and Instruction: Theory. Dordrecht, The Netherlands, 2001.

[21] H. L. Burns, C. G. Capps. Foundations of Intelligent Tutoring Systems: an introduction. In Foundations of Intelligent Tutoring Systems. Mahwah, NJ, 1988.

[22] H. Seffrin, G. Rubi, T. Carlotto, G. Mello, P. A. Jaques. Um resolvedor de equações algébricas como ferramenta de apoio à sala de aula no ensino de equações algébricas. In Anais do XV Workshop sobre Informática na Escola. Bento Gonçalves, 2009.

[23] H. Seffrin, P. Jaques. Avaliando o conhecimento algébrico dos estudantes através de Redes Bayesianas Dinâmicas. Anais do XXVI Simpósio Brasileiro de Informática na Educação (SBIE 2015). Maceió, Alagoas, 2015.

[24] J. C. Lester, S. A. Converse, S. E. Kahler, S. T. Barlow, B. A. Stone, R. S. Bhogal. The persona effect: Affective impact of animated pedagogical agents. SIGCHI conference on Human factors in computing systems. Atlanta, 1997.

[25] J. Dunlosky; J. Metcalfe. Metacognition. Los Angeles, 2009.

[26] J. H. Flavell. Metacognition and cognitive monitoring: A new area of cognitive-developmental inquiry. American Psychologist. 1979.

[27] J. H. Flavell. Metacognitive aspects of problem solving. In The nature of intelligence. Hillsdale, 1976.

[28] J. Psotka; L. D. Massey, S. A. Mutter. Introduction. In Intelligent Tutoring Systems: Lessons Learned. Hillsdale, New Jersey, 1988.

[29] K. Bielaczyk, P. L. Pirolli, A. L. Brown. Training in Self-Explanation Strategies: SelfRegulation the Effects of Investigating Knowledge Acquisition Activities on Problem Solving. Cognition and Instruction. New York, 1995.

[30] K. R. Koedinger, V. Aleven. Exploring the Assistance Dilemma in Experiments with Cognitive Tutors. Educational Psychology Review. 2007.

[31] K. Stavrianopoulos. Adolescent's Metacognitive Knowledge Monitoring and Academic Help Seeking: The Role of Motivation Orientation. College Student Journal. Alabama, 2007.

[32] K. VanLehn. The Behavior of Tutoring Systems. International Journal of Artificial Intelligence in 
Education. Amsterdam, The Netherlands, 2006.

[33] K. VanLehn. The Relative Effectiveness of Human Tutoring, Intelligent Tutoring Systems, and Other Tutoring Systems. Educational Psychologist. New York, NY, 2011.

[34] L. Verschaffel. Realistic mathematical modelling and problem solving in the upper elementary school: analysis and improvement. In Teaching and learning thinking skills. Lisse, The Netherlands, 1999.

[35] L. Vygotsky. Interaction Between Learning and Development. Mind and Society. Cambridge, MA, 1978.

[36] L.J. Cronbach, P.E. Meehl. Construct validity in psychological tests. Psychological Bulletin. Páginas 281-302, 1955.

[37] M. Bannert. Effects of reflection prompts when learning with hypermedia. Journal of Educational Computing Research. Los Angeles, 2006.

[38] M. G. M. Fergusson-Hessler, T. Jong. Studying Physics Texts: Differences in Study Process Between Good and Poor Performers. Cognition and Instruction. Mahwah, NJ, 1990.

[39] M. T. H. Chi, M. Bassok, M. W. Lewis, P. Reimann, R. Glaser. Self-Explanations: How Students Study and Use Examples in Learning to Solve Problems. Cognitive Science. Austin, TX, 1989.

[40] M. T. H. Chi, N. de Leeuw, M. Chiu, C. Lavancher. Eliciting Self-Explanations Improves Understanding. Cognitive Science. Austin, TX, 1994.

[41] M. T. Ullman. Contributions of memory circuits to language: the declarative/procedural model. Cognition. The Netherlands, 2004.

[42] M. V. J. Veenman, B. H. A. M. V. HoutWolters, P. Afflerbach. Metacognition and learning: conceptual and methodological considerations. Metacognition Learning. Dordrecht, The Netherlands, 2006.

[43] M. V. J. Veenman, B. H. A. M. Van HoutWolters, P. Afflerbach. Metacognition and learning: conceptual and methodological considerations. Metacognition Learning, 2006.

[44] Mary A. Mark; Jim E Greer. Evaluation methodologies for intelligent tutoring systems. Journal of Interactive Learning Research. 1993.

[45] N. Jennings, K. Sycara, M. Wooldridge. A Roadmap of agent research and development.
Journal of Autonomous Agents and Multi-Agent Systems. 1998.

[46] P. A. Jaques, H. Seffrin, G. Rubi, F. de Morais, C. Ghilardi, I. I. Bittencourt, S. Isotani. Rulebased expert systems to support step-by-step guidance in algebraic problem solving: the case of the tutor PAT2math. Expert Systems with Applications. Dordrecht, The Netherlands, 2013.

[47] P. A. Jaques, M. A. S. N Nunes. Ambientes Inteligentes de Aprendizagem que inferem, expressam e possuem emoções e personalidade. In Jornada de Atualização em Informática na Educação. Natal, Brasil, 2012.

[48] P. R. Pintrich, C. A. Wolters; G. P. Baxter. Assessing Metacognition and Self-Regulated Learning. In Issues in the measurement of metacognition. Lincoln, NE, 2000.

[49] R. Azevedo, A. F. Hadwin. Scaffolding Selfregulated Learning and Metacognition - Implications for the Design of Computer-based Scaffolds. Instructional Science. Dordrecht, Netherlands, 2005 .

[50] R. Azevedo, A. F. Hadwin. Scaffolding Selfregulated Learning and Metacognition - Implications for the Design of Computer-based Scaffolds. Instructional Science. Dordrecht, Netherlands, 2005.

[51] R. Azevedo, J. Harley, G. Trevors, M. Duffy, R. Feyzi-Behnagh, F. Bouchet, R. Landis. Using Trace Data to Examine the Complex Roles of Cognitive, Metacognitive, and Emotional SelfRegulatory Processes During Learning with Multi-agent Systems. In International Handbook of Metacognition and Learning Technologies. New York, 2013.

[52] R. Azevedo, R. F. Feyzi-Behnagh, M. Duffy, J. M. Harley, G. Trevors. Metacognition and selfregulated learning in student-centered leaning environments. In Theoretical foundations of student-center learning environments. Routledge, NY, 2012.

[53] R. Azevedo, R. F. Feyzi-Behnagh, M. Duffy, J. M. Harley, G. Trevors. Metacognition and selfregulated learning in student-centered leaning environments. In Theoretical foundations of student-center learning environments. New York, 2012.

[54] R. Azevedo, V. Aleven. International Handbook of Metacognition and Learning Technologies. Pittsburgh, PA, USA, 2013. 
[55] R. E. Mayer. Applying the Science of Learning. Boston, MA, 2011.

[56] R. Fogarty. How to Teach for Metacognitive Reflection. Pearson, Glenview, 1994.

[57] S. Russel, P. Norvig. Inteligência Artificial. Rio de Janeiro, 2013.

[58] S. Steenbergen-Hu, H. Cooper. A meta-analysis of the effectiveness of intelligent tutoring systems on $\mathrm{K}-12$ students' mathematical learning. Journal of Educational Psychology. 2013.

[59] S. Steenbergen-Hu, H. Cooper. A meta-analysis of the effectiveness of intelligent tutoring systems on college students' academic learning. Journal of Educational Psychology. 2014.

[60] S. Tobias e H. T. Everson. The Importance of Knowing What You Know: A Knowledge Monitoring Framework for Studying Metacognition in Education. In Handbook of Metacognition in Education. New York, NY, Routledge, 2009.

[61] S. Tobias, H. Everson. Assessing Metacognitive Knowledge Monitoring. In Issues in the measurement of metacognition. Lincoln, NE, 2000.

[62] S. Tobias, H. Everson. The Importance of Knowing What You Know: A Knowledge Monitoring Framework for Studying Metacognition in Education. In Handbook of Metacognition in Education. New York, NY, 2009.

[63] S. Tobias, H. T. Everson. Knowing what you Know and what you don't: Further Research on Metacognitive Knowledge Monitoring. In College Board Research Report. New York, 2002.

[64] V. Aleven, B. Mclaren, K. Koedinger, I. Rool: Toward Metacognitive Tutoring: A Model of Help-Seeking with a Cognitive Tutor. International Journal of Artificial Intelligence in Education. 2006.

[65] W. Ma, O. O. Adesope, J. C. Nesbit, Q. Liu. Intelligent Tutoring Systems and Learning Outcomes: A Meta-Analysis. Journal of Educational Psychology. Washington, 2014.

[66] X. Lin. Designing Metacognitive Activities. Educational Technology Research and Development. Netherlands, 2001. 